\title{
Cell-Intrinsic and Extrinsic Effects of Galectin-1 and Galectin-3 in B-Cell Precursor Acute Lymphoblastic Leukemia
}

\author{
Fei Fei ${ }^{1}$, Eun Ji Joo², Lu Yang ${ }^{2}$, John Groffen ${ }^{1}$ and Nora Heisterkamp ${ }^{2, *}$ \\ 1 Section of Molecular Carcinogenesis, Department of Pediatrics, Division of \\ Hematology/Oncology and Bone Marrow Transplantation, The Saban Research Institute \\ of Children's Hospital Los Angeles, CA 90027, USA \\ 2 Department of Systems Biology, Beckman Research Institute City of Hope, Monrovia, CA, \\ USA \\ * Correspondence: eheisterkamp@coh.org; Tel.: +1-626-218-7503
}

Author Contributions: FF designed and executed experiments, analyzed and interpreted data; EJJ designed and executed experiments, analyzed data; LY analyzed data; JG designed experiments and interpreted data; $\mathrm{NH}$ designed experiments, analyzed and interpreted data and wrote the manuscript. All authors reviewed the manuscript.

Conflicts of Interest: The authors declare no conflict of interest. The funding sponsors had no role in the design of the study; in the collection, analyses, or interpretation of data; in the writing of the manuscript, and in the decision to publish the results.

This PDF file includes:

Main Text

Figures 1 to 7

Figure $\mathrm{S} 1$ 


\begin{abstract}
Acute lymphoblastic leukemias arising from the malignant transformation of B-cell precursors (BCP-ALLs) are protected against chemotherapy by both intrinsic factors as well as by interactions with bone marrow stromal cells. Galectin-1 and Galectin-3 have overlapping expression patterns and potentially common functions in these cells. We used Galectin-1 and Galectin-3 double null mutant murine BCP-ALL cells to examine the effect of loss endogenous Galectins. We also tested the effect of Galectin inhibition by use of plant-derived natural compounds GM-CT-01 and GR-MD-02 in human BCP-ALL cells in co-culture with stroma. Transformed wild type and Galectin-1 x Galectin-3 double knockout BCP-ALL cells were similar in immunophenotype and active intracellular signaling. However, compared to wild type cells, they showed impaired migration, significantly reduced proliferation and increased sensitivity to drug treatment. GM-CT-01 and GR-MD-02 attenuated intracellular signal transduction and sensitized the BCP-ALL cells to chemotherapy including vincristine and the targeted tyrosine kinase inhibitor nilotinib. Our data show endogenous and extracellular Galectins contribute positively to the growth and survival of BCP-ALL cells. Strategies that would efficiently ablate both Galectins at both locations would decrease microenvironmental protection and reduce BCP-ALL persistence in the protective bone marrow niche after chemotherapy.
\end{abstract}

Keywords: acute lymphoblastic; Bcr/Abl; Galectin-1; Galectin-3; microenvironment; OP9 stromal; double knockout; GM-CT-01; GR-MD-02; combination drug treatment; migration

\title{
1. Introduction
}

B-cell precursor acute lymphoblastic leukemias (BCP-ALLs) constitute a group of developmentally arrested, immature B-lineage precursors, which can be categorized into numerous subgroups based on genetic abnormalities (1-4). Ph-chromosome positive ALL (Ph-positive ALL) is one major poor-prognosis subcategory of ALL, characterized by the presence of a $t(9 ; 22)$ translocation which fuses two genes, $B C R$ and $A B L$, at the breakpoints (5). The chimeric Bcr/Abl protein that is produced as a result has deregulated tyrosine kinase activity which can be inhibited by targeted small molecule inhibitors such as nilotinib (6). This type of leukemia can be studied in the murine system making use of $B C R / A B L$ transgenic mice or by generating BCP-ALL from mouse bone marrow by transduction with a retrovirus encoding human Bcr/Abl $(7,8)$.

Other BCP-ALLs involve transcription factors, such as the fusion of ETV6 and Runx1 (9) or recombination of different genes with the MLL gene (10). All the BCP-ALLs do have a common anatomical site of origin however- the bone marrow microenvironment- and this is also the most frequent location of relapse during or after chemotherapy (11). In fact, drug resistance development of cancer cells is actively promoted by their microenvironment (12, 13). We and others (14-19) are able to model BCP-ALL drug resistance development ex vivo, because BCP-ALL cells from patients can proliferate if supported by bone marrow stromal cells. Chemotherapy treatment of such co-cultures of primary or PDX-derived human BCP-ALL cells with OP9, a murine bone marrow stromal cell line, allows the persistence of drug-insensitive cells. The OP9 cells are a major source of SDF $1 \alpha$, which, as a main chemokine, attracts leukemia cells and promotes their adhesion in the bone marrow $(20,21)$. The migration towards and adhesion to bone marrow stroma is one mechanism that contributes to chemoprotection provided by stromal cells to BCP-ALL but overall, the mechanisms through which such bone marrow stromal cells promote BCP-ALL drug resistance are incompletely understood.

Although soluble factors are also important, the close association between the BCP-ALL and stromal cells is needed for optimal protection against chemotherapy. There is increasing 
evidence that both Galectin-1 and Galectin-3 are involved in the protective cross-communication between leukemia cells and the microenvironment. Our data identified Galectin-3, a carbohydrate-binding protein that cross-links polyLacNAc-modified glycoproteins on the cell surface $(22,23)$, as promoting migration and adhesion of BCP-ALL cells to stromal cells, which are a source of secreted Galectin-3. We showed that drug-treated BCP-ALL cells also synthesize Galectin-3 endogenously (24).

Juszczynski et al. previously reported that only BCP-ALL cells containing MLL rearrangements expresses Galectin-1 endogenously (25). Our own studies determined that expression of Galectin-1 is more ubiquitous and is also present in other subcategories of BCP-ALL including Ph-positive ALL (26). Interestingly, Galectin-1 was shown to be a ligand for the pre-B-cell receptor in normal precursor B cells (27). In fact, bone marrow stromal cells that secrete Galectin-1 may represent a specific niche in the bone marrow for normal BCP development (28). It is moreover possible that such cells produce both Galectin-1 and Galectin-3: equine bone marrow stromal cells express both Galectin-1 and Galectin-3 mRNA (29), and our own studies showed that OP9 murine bone marrow stromal cells produce exosomes containing both Galectins (24). Thus, there is evidence that both the bone marrow microenvironment as well as BCP-ALL cells can express, secrete and/or endocytose both Galectin-1 and Galectin-3.

In the current study, we addressed the combined importance of Galectin-1 and Galectin-3 in Ph-positive/Bcr-Abl-expressing BCP-ALL. To examine endogenous Galectins, we generated BCP-ALL cells from Lgals $1 \times$ Lgals3 double null mutant mouse bone marrows by transduction with the Bcr/Abl oncogene. In addition, we sought to inhibit extracellular Galectin-1/-3 making use of function-inhibitory compounds. As reviewed in (30), compounds that have inhibitory activity against both Galectin-1 and Galectin-3 include the disaccharide small molecule TD139 (31) and relatively high molecular weight (50-60 kDa) carbohydrates derived from natural plant glycans such as GM-CT-01 and GR-MD-02 (32-35). Since the in vitro Kds of both compounds were reported to be comparable [GR-MD-02: Galectin-1 $10 \mu \mathrm{M}$, Galectin-3 2.9 $\mu \mathrm{M}$; GR-CT-01: $8 \mu \mathrm{M}$ and $2.8 \mu \mathrm{M}$ ] they would be expected to inhibit both extracellular Galectins. Because such compounds progressed to testing in clinical trials we investigated their effect on BCP-ALL cells when these are grown with stromal support as a source of extracellular Galectin-1 and Galectin-3.

\section{Results}

\subsection{Expression of Galectin-1 and Galectin-3 in BCP-ALL}

We first determined if Galectin-1 and Galectin-3 mRNAs are simultaneously expressed in Ph-positive BCP-ALL cells by meta-analysis of human gene array expression data sets for transcripts of these genes. The majority of samples in two gene array data sets, representing a total of 33 primary cases of Ph-positive ALL, simultaneously expressed both Galectin-3 and Galectin-1 mRNAs (not shown). Interestingly, one data set showed a positive correlation $\left(R^{2}=0.46 \& p<0.01\right)$ between expression of these two genes, suggesting that in some cases their expression may be linked (Figure 1a). In the tel-AML1 subcategory of BCP-ALL, expression was also positively correlated $\left(R^{2}=0.26 \& p<0.0001, R^{2}=0.16 \& p<0.01\right)$ (Figure $1 \mathrm{~b}$ ) but a similar analysis of MLL-rearranged BCP-ALLs showed no correlation (data not shown), indicating that this may be subtype-dependent.

Mouse models for Ph-positive ALL include transgenic mice that develop ALL within around 3 months after birth. We analyzed a data set of such samples (GSE110104) consisting of flow-sorted bone marrow cells from matched wild type, preleukemic, fully leukemia and fully leukemic mice treated for 8 days with nilotinib, a targeted Bcr/Abl kinase inhibitor $(36,37)$. Whereas the absolute values for Galectin-1 expression were higher than those for Galectin-3 (compare MFI values right and left panel Figure 1c), both non-leukemic wild type and 
leukemic BCP samples expressed both Galectins. Expression levels of Galectin-1 were comparable in the samples. Consistent with our previous results in human ALL cells treated with drugs (24), the expression of Galectin-3 was significantly induced in drug-treated BCP-ALL cells which we isolated from mice that had been treated for 8 days with $75 \mathrm{mg} / \mathrm{kg}$ nilotinib.

\subsection{Galectin-1 x Galectin-3 double null mutant BCP-ALL cells have decreased proliferation and survival}

To investigate the effect of simultaneous loss of Galectin-3 and Galectin-1 function on BCP-ALL cells, we used transformation of primary B-lineage murine bone marrow cells by the $\mathrm{P} 190 \mathrm{Bcr} / \mathrm{Abl}$ oncogene to generate an aggressive, well-proliferating B-cell precursor ALL that does not depend on stromal support. Early passage immunophenotyping of two independently transduced sets of wild type (wt) and Lgals1 x Lgals3 -/- (hereafter referred to as $\mathrm{dKO}$ ) BCP-ALL cells showed they were similar in that they lacked surface IgM, but were positive for CD43, B220 and AA4.1 (Figure 2a). Samples were heterogeneous for expression of the BAFF-R and CD24 (Figure S1 panel a). Western blotting of early passage cells grown without stroma confirmed lack of Galectin-1 (Figure 2b). As expected, based on expression of the Bcr/Abl tyrosine kinase, these cells contained many tyrosine phosphorylated proteins (Figure 2b, pY20 Western blot panel) as a consequence of the deregulated tyrosine kinase activity of this oncoprotein, but this did not reveal clear differences between wt and dKO cells in commonly activated signal transduction pathways in this type of leukemia cells including Stat5, Erk, p38 or Akt. However, levels of p-Src were increased in the dKO cells.

Endogenous Galectin-3 was only detected in wt1 cells grown alone (Figure 2c) and this was significantly less than the amount of Galectin-3 present in lysates of the murine bone marrow stromal cell line OP9. When the murine BCP-ALL were exposed to Galectin-3 made by OP9 stromal cells through co-culture, three of the four BCP-ALLs endocytosed Galectin-3 detectable by Western blot (Figure 2c).

Physiologically, wt and dKO cells were clearly different. Whereas wild type BCP-ALL cells had robust cell growth, loss of both endogenous Galectin-1 and -3 resulted in considerably reduced proliferation rates (Figure 3a). Using murine BCP-ALL Lgals3-/- cells, we previously showed that endogenous expression of Galectin-3 provides protection to the BCP-ALL cells against chemotherapy (38). Using pharmacological inhibition of Galectin-1, we also have evidence that the expression of endogenous Galectin-1 provides chemoprotection (26). Therefore, we compared the growth and survival of wt murine BCP-ALL cells to that of the dKO cells under drug treatment.

Cells were treated with a non-lethal dose of vincristine, one component of the standard induction chemotherapy regimen for BCP-ALL. As shown in Figure 3b (left panels), wt1 or wt2 BCP-ALL cells treated with vincristine showed an initial drop in viability, but resumed proliferation as the cells become resistant to the chemotherapy (Figure $3 \mathrm{~b}$ right panels). However, the viability of dKO1 or dKO2 BCP-ALL cells treated with vincristine did not recover after 4-5 days of drug exposure and no cell growth was measured (Figure $3 \mathrm{~b}$ ).

As shown for wt1 (Figure 3d, left) and wt2 (Figure 3f, left), stromal cells (including MEFs, mouse embryonic fibroblasts) provide significant protection to human BCP-ALL cells against many types of drug treatment $(14,15,17-19)$. To examine if co-culture with stromal cells could compensate to any degree for lack of endogenous Galectin-1 and Galectin-3 in double null mutant cells, we compared the growth and survival of dKO cells BCP-ALL cells, cultured with and without MEFs during nilotinib treatment. As shown for wt1 (Figure 3c, left) and wt2 (Figure 3d, left), consistent with their stromal independence, wt BCP-ALL cells had similar viability with or without co-culture with MEFs. Moreover, viability was minimally affected by nilotinib treatment. Nilotinib was cytostatic for the growth of wt1 (Figure 3c, right) and wt2 (Figure 3d, right), and the presence of MEFs had no positive effect on proliferation. For dKO1 
(Figure 3c) and dKO2 (Figure 3d), nilotinib treatment decreased their viability, but the presence of MEFs significantly improved this (Figure 3c, d left panels) indicating that some of the cells survived over the duration of the treatment. However, there was still little proliferation. (Figure 3c, d right panels).

\subsection{Galectin-1 and Galectin-3- stimulation of migration}

Stromal cells produce SDF1 $\alpha$, the main chemoattractant for BCP-ALL cells $(19,39)$. Therefore, when BCP-ALL cells are introduced into a Transwell that has a stromal layer on the bottom, they migrate into the bottom compartment. As shown in Figure 4a, lack of endogenous Galectin-1 and Galectin-3 reduced migration of mouse Bcr/Abl-expressing BCP-ALL cells towards MEFs, indicating that cell-endogenous Galectins contribute to efficient migration.

To also evaluate the effect of extracellular Galectins on migration, we used a human Bcr/Abl expressing (Ph-positive) ALL, TXL2, in co-culture with OP9 stromal cells as a source of Galectins. We used the galactomannan GM-CT-01 and the galactoarabino-rhamnogalaturonan GR-MD-02 $(33,35)$ as inhibitors of extracellular Galectin-1/-3. Figure 4b shows that at high concentrations, GM-CT-01 reduced migration of TXL2 towards OP9 stroma. GR-MD-02 (Figure 4d) was active in inhibition of cell motility at lower concentrations than GM-CT-01. The effect of these compounds was not restricted to BCP-ALLs that express Bcr/Abl, as a similar effect was measured in US7, a human BCP-ALL that does not contain the Bcr/Abl oncogene or other known genetic abnormalities (Figure 4c, e).

\subsection{Intracellular interaction of Galectin-3 with $A b l$}

Actin cytoskeletal reorganization is essential for cell migration, and in some cell types Abl was shown to play a critical role in regulating actin dynamics (40). In leukemias with a $B C R / A B L$ translocation, the actin binding domain of $\mathrm{Abl}$ is retained in the fusion protein and the Bcr/Abl protein associates with the actin cytoskeleton via the Abl actin-binding domain. Thus Bcr/Abl also regulates cell migration $(41,42)$. Interestingly, Galectin-3 was shown to form a protein complex with Abl in prostate and breast cancer cell lines and becomes phosphorylated on tyrosine (43-45).

The Ph-translocation is the defining characteristic of chronic myelogenous leukemia $(\mathrm{CML})$, another leukemia that expresses a Bcr/Abl fusion protein. We made use of the $\mathrm{CML}$ cell line K562, because it contains multiple copies of the $B C R / A B L$ gene (46), to determine if $\mathrm{Bcr} / \mathrm{Abl}$ and Galectin-3 also interact. Moreover, this cell line also synthesizes Galectin-3 endogenously (47). As shown in Figure 5a (lane total lysate, immunoblotted with Galectin-3 antibodies), we confirmed that K562 cells express Galectin-3 protein endogenously in the absence of stromal cells. Interestingly, Galectin-3 was detected in immunoprecipitates with Bcr/Abl using two different anti-c-Abl monoclonal antibodies (Figure 5a, IP Abl 3F12 or IP Abl Ab-3; bottom panel, Galectin-3 WB). To determine if Galectin-3 becomes tyrosine phosphorylated in these cells, we immunoprecipitated Galectin-3 and used anti-PY20 antibodies to examine the precipitated protein. Figure 5b (right panel: IP Gal3, IB pY20) shows that Galectin-3 is tyrosine phosphorylated and confirmed it is detected in the Bcr/Abl immunoprecipitate (left panel: IP 3F12, IB: Gal3)).

To investigate if exogenous Galectin-3 provided by stroma also interacts with Abl, we co-cultured the K562 with MEFs, prepared lysates, and preformed immunoprecipitations with anti-Abl 3F12 antibodies. As shown in Figure 5c, compared to K562 cultured alone, the co-cultured cells contained a higher molecular Galectin-3 weight band (compare lanes 2 and 4, Gal-3 WB). This band represents murine Galectin-3: human Galectin-3 (UniProt P17931) consists of 250 amino acid residues, whereas mouse Galectin-3 (UniProt 16110) contains 264 amino acids (Figure S1 panels b, c; also see Figure 6b). The mouse Galectin-3 as well as the endogenous human Galectin-3 co-immunoprecipitated with Bcr/Abl (Figure 5c, double 
band in IPs from K562+MEF lysates, 3F12 IPs, Galectin-3 WB). Re-probing of the membrane with anti-Crkl antibodies showed that Crkl had also been co-immunoprecipitated with Bcr/Abl as expected (48). These results suggest that both endogenously produced as well as exogenous Galectin-3 bound to or taken up by K562, can interact intracellularly with (Bcr)/Abl.

To confirm that Bcr/Abl indeed forms a complex with exogenously produced Galectin-3, we immunoprecipitated Bcr/Abl from human Ph-positive BLQ1 ALL cells. These do not express much Galectin-3 endogenously under steady state conditions (24). Figure 5d (IP 3F12 IB: Galectin-3) shows that we also detected co-immunoprecipitation of Bcr/Abl with Galectin-3 in BLQ1 ALL cells, indicating that mouse Galectin-3 and human Bcr/Abl also interact. As we also detected co-immunoprecipitation of c-Abl with Galectin-3 in US7 cells, which are Ph-chromosome negative and do not contain Bcr/Abl (Figure 5d), interaction of Abl with Galectin-3 may be a common mechanism that could regulate migration of BCP-ALL cells.

\subsection{Effect of GM-CT-01 or GR-MD-02 on ALL signaling}

OP9 stromal cells synthesize and secrete high levels of Galectin-3 (24). As mentioned, our studies have shown that under non-stressed conditions, the Galectin-3 on and inside BCP-ALL cells mainly originates from the OP9 stromal cells in the tissue co-culture model. We therefore investigated if GM-CT-01 could reduce binding of Galectin-3 to BCP-ALL cells. We harvested ALL cells from underneath the stroma and stained the ALL cells for Galectin-3 with or without prior incubation with GM-CT-01. As shown in Figure 6a, binding of Galectin-3 antibody to the cells was reduced in the presence of GM-CT-01, providing evidence that the compound is able to decrease cell surface-bound Galectin-3 on these cells.

To compare the effect of GM-CT-01 on extracellular and intracellular Galectin-3, we generated lysates of K562 alone or in co-culture with MEFs, after treatment, or not, with GM-CT-01. As shown in Figure 6b, when these cells are plated on MEFs and the samples are run on a lower percentage SDS-PAA gel, an additional band is visible with a slightly larger molecular mass, representing murine Galectin-3. Interestingly, treatment with GM-CT-01 reduced the signal from the murine Galectin-3 (Figure 6b, lane 5; also see Figure 5c lane 6 panel Gal3 immunoblot), supporting the proposed reduction by this compound of extracellular Galectin-3 bound to leukemia cells. $50 \mathrm{mM}$ lactose as a competitor had minimal effects on the endogenous Galectin-3 in K562 (Figure 5c lane 2). Compared to $20 \mathrm{mg} / \mathrm{ml}$ GM-CT-01, it also did not reduce mouse Galectin-3 detected in the K562 lysates (Figure 5c lane 5 and Figure $6 \mathrm{~b}$ lane 5).

We have previously shown that BCP-ALL cells treated with chemotherapy including vincristine also induce endogenous production of Galectin-3 (24), as illustrated in Figure 6c (compare lane 1, no treatment to lane 2, vincristine treatment). Interestingly, GM-CT-01 treatment reduced Galectin-3 levels both in non-vincristine as well as vincristine-treated cells (lanes 3 and 4). We next analyzed the possible consequences of this treatment on intracellular signaling. Figure $6 \mathrm{~d}$ shows that a 3-day treatment with GM-CT-01 attenuated pErk1/2 signals in both US7 and TXL2 cells and also reduced endogenous levels of p-p38. We also treated cells with GR-MD-02. As shown in Figure 6e, similar to GM-CT-01, the phosphorylation of p38 and Erk1/2 was reduced by this compound, whereas Akt and STAT5 phosphorylation were not visibly affected. Cytoplasmic NF-kB p-p65 and NF-kB p65 levels were also decreased after long-term exposure to GR-MD-02 (Figure 6f).

\subsection{GM-CT-01 or GR-MD-02 inhibit proliferation of ALL cells in the presence of stromal support}

We examined whether GM-CT-01 alone or in combination with therapeutic drugs affects the viability of ALL cells in the presence of OP9 stromal cells. As shown in Figure 7a, whereas 
GM-CT-01 alone had no obvious effect on TXL2 ALL cells, the addition of GM-CT-01 to nilotinib-treated cells further decreased cell viability and cell numbers beyond nilotinib mono-treatment. The compound also significantly reduced US7 ALL cell viability beyond that of vincristine mono-treated cells (Figure 7b) and had a visible effect on US7 leukemia cells when combined with vincristine (Figure 7c).

We additionally evaluated GR-MD-02. This compound was effective at lower concentrations than GM-CT-01. Similar to GM-CT-01, the compound had little effect on the viability of the cells as monotreatment (Figure 7d, e, left panels GR-MD-02 alone) but did inhibit proliferation of both TXL2 (Figure 7d, right panel) and US7 (Figure 7e right panel) as measured by a reduction in the total viable cell count. Nilotinib as tyrosine kinase inhibitor is not extremely cytotoxic, but its combination with relatively lower amounts of GR-MD-02 (Figure $7 \mathrm{~d}$, right panel, $1 \mathrm{mg} / \mathrm{ml}$ and lower) produced a significant reduction in cell counts. GR-MD-02 with vincristine (Figure 7e left panel) also had increased toxicity at 2.5 and 5 $\mathrm{mg} / \mathrm{ml}$ compound and a cytostatic effect on the US7 ALL cells, at $5 \mathrm{mg} / \mathrm{ml}$ (Figure 7e, right panel).

\section{Discussion}

\subsection{Overlapping expression of Galectin-3 and Galectin-1}

Galectin-1 and Galectin-3 have each been widely studied in the context of cancer and as modulators of activities of different types of immune cells. Based on gene array expression data of, for example, human NK cells (GSE27838) or OP9 (GSE56472 (49)), our own results with OP9 cells (24), measurements in equine mesenchymal bone marrow stromal cells (29), as well as a phenotype seen in dKO (Galectin-1 x Galectin-3) murine reactive astrocytes (50), it is not unusual for the same cells to express both Galectin-1 and Galectin-3. We found that many primary BCP-ALL samples also contain both Galectin-1 and Galectin-3 mRNA, raising the question how these cells would be affected by simultaneous ablation of both Galectins. In other cell types, their function has some overlap, as illustrated by the fact that both proteins have binding partners in common, such as von Willebrand factor, the lysosomal protein Lamp1 (51-53) and the mature B-cell transcription factor OCA-B (54). Also, both Galectin-1 and Galectin-3 regulate mature B-cell functions in a mouse model of autoimmune disease (55) and ablation of both Galectin-1 and Galectin-3 in SV40-immortalized mouse embryonic fibroblasts strongly downregulated K-Ras and downstream Erk and Akt activation (56). In our murine BCP-ALL cells, we did not detect differences in Erk or Akt activation in dKO cells compared to wt, although the dKO cells were functionally distinct from the wt cells. It is possible that we did not detect differences because of our use of Bcr/Abl as driver oncogene, which obviates the need for exogenous cytokine signaling and makes these BCP cells IL-7 independent, while activating multiple signal transduction pathways endogenously (8). Nonetheless, the double knockout Galectin-1 and Galectin-3 murine BCP-ALL cells proliferated significantly less well than wild type controls, indicating that the cells clearly are defective in some aspects of mitogenic signaling, or have other endogenous deficiencies related to for example cell cycle progression.

Interestingly, we did detect increased tyrosine phosphorylation of an activating tyrosine residue common to a number of Src-family kinases (SFK) such as Lck and Lyn, in the double knockout cells. These antibodies are directed against Y419 in Src but may also react with Y394 in Lck, or Y397 in Lyn, both of which are also highly expressed in BCP-ALL. This residue can be dephosphorylated by the transmembrane phosphatase CD45 $(57,58)$. Although it will require further investigation, Galectin-1 could regulate the basal and activating signaling of such SFK through binding to the extracellular domain of CD45 and regulating its enzymatic activity towards SFK as reported in T cells $(59,60)$. 
It is possible that the proliferation defect of the dKO cells also causes the greater vulnerability to nilotinib or vincristine monotherapy. However, this does not explain why dKO cells have impaired migration towards stromal cells, as cell division is not needed for this. Interestingly, the proliferation defects of the dKO cells were mitigated by co-culture with a fibroblast stromal layer, and their ability to withstand drug treatment was also enhanced by the presence of these cells. Therefore, it is likely that the stromal layer is providing some of the missing functions, which, on a molecular level, could include the production and secretion of Galectin-3 and Galectin-1 by this cell type (24).

\subsection{High molecular weight compounds to inhibit extracellular Galectin-1 and Galectin-3.}

Our co-culture system of leukemia cells with stromal cells is intended to model the bone marrow microenvironment, where leukemia cells are also protected and supported. In this complex system, the leukemia cells have two sources of Galectin-1 and Galectin-3: that secreted by the stromal cells, which can bind to the cell surface of the leukemia cells and become endocytosed, and that produced endogenously by the leukemia cells, of which an unknown fraction is transported to the cell surface and/or secreted. Because human and mouse Galectin-3 differ in molecular weight (Figure S1 panel c), we were able to distinguish the two sources. A Western blot for Galectin-3 in total lysates of leukemia cells is expected to only report on intracellular or strongly cell-surface bound Galectin-3. We found that GM-CT-01 clearly reduced the amount of the stromal-produced Galectin-3 associated with the leukemia cells (also see Figure S1 panel b), but it had less effect on the Galectin-3 that had been made by the leukemia cells. Also, no effect on Galectin-1 levels in K562 lysates was seen (Figure S1 panel b). This is consistent with the concept that such compounds, because of their relatively large size, mainly have an effect on displacement of extracellular Galectins.

It is generally assumed, that extracellular Galectin-3 depends on its carbohydrate-binding function, which is needed to promote lattice formation of poly-LacNAc modified glycoproteins and stimulate subsequent receptor clustering. This is known to enhance intracellular signal transduction. In concordance with this, in our study, blocking of Galectin-3/Galectin-1 by GM-CT-01 or GR-MD-02 down-regulated levels of p-Erk1/2 and p-p38, but no effects on the Akt pathway were seen. In contrast, in myeloma cells, treatment with a different compound, the pectin-derived GCS-100 reduced activation of Akt (61). Thus, the effects of compounds such as GM-CT-01 or GR-MD-02 may depend on which target glycoproteins are bound by Galectin-3 or Galectin-1 on different cell types. We found that both GR-MD-02 and GM-CT-01 inhibited activation of the Erk pathway in Bcr/Abl-positive and non-Bcr/Abl-transformed human ALL cells, suggesting that such compounds have a general effect such as interfering with the migration of the BCP-ALL cells to the stroma and/or reducing contact with it. Chauhan et al. (62) observed that GCS-100 overcame bortezomib resistance and enhanced dexamethasone-induced apoptosis in multiple myeloma cells. Streetly et al. (61) reported similar results. This is consistent with our data which show that such compounds in combination with a therapeutic drug additionally enhance the effects of those drugs in the presence of microenvironmental protection in vitro.

We used GR-MD-02 and GM-CT-01 as dual Galectin-1 / Galectin-3 inhibitors based on in vitro data reporting that the Kds of GM-CT-01 and GR-GM for Galectin-1 and Galectin-3 are similar (30). However, both compounds have been used as if they mainly inhibit extracellular Galectin-3 [GM-CT-01 (63)] [GR-MD-02 (64-67)]. Whether this is a reasonable assumption is not clear: in vitro, GM-CT-01 does interact with Galectin-1, with a domain that does not include the classical carbohydrate-binding site (33). Moreover, Stegmayr et al (68) reported a GM-CT-01 IC 50 of $4 \mathrm{mg} / \mathrm{ml}$ for Galectin-3 and $>20 \mathrm{mg} / \mathrm{ml}$ for Galectin-1 in an inhibitory binding assay to ASF. These high concentrations are in agreement with the concentrations of GM-CT-01 needed to obtain a biological effect in our studies, and raise the concern for off-target effects. Thus, although the use of these compounds supports the premise that 
inhibition of the interaction of stromal-produced Galectin-3 and Galectin-1 is useful to chemosensitize BCP-ALL cells, a need remains for the development of more specific and potent inhibitors such as anti-Galectin-3 antibodies (69), novel carbohydrate mimetics [Bum-Erdene et al; Tarighat et al, in preparation] or peptides [Battacharya et al, in preparation].

\subsection{Conclusion}

Overall, our studies suggest that the homing of ALL cells to the close proximity of protective stromal cells, such as are present in the bone marrow, is important and may result in the persistence of drug-insensitive cells that can give rise to relapse. Thus carbohydrate-based drugs that interfere with the binding of stromal-produced Galectin-3 and Galectin-1 to the surface of BCP-ALL cells may prevent firm adhesion contacts from forming between the two cell types, and sensitize the ALL cells to cytotoxic drugs. Our previous results showed that endogenous Galectin-3 expression protects human BCP-ALL cells against chemotherapy (38). Therefore, a strategy of combined inhibition of Galectin-1 and Galectin-3 function, both extracellularly and intracellularly, using small molecule inhibitors, may be specifically potent in chemo-sensitizing BCP-ALL cells.

\section{Materials and Methods}

\subsection{Gene expression analysis}

Meta-analysis of LGALS3 and LGALS1 (Galectin-3 and Galectin-1) expression of RNAs from pediatric $\mathrm{Ph}$-positive ALL at diagnosis was performed on data sets from GEO Datasets accession GSE28497 and GSE79533, described in (70) and in (71), respectively. Processed data in the series matrix files represent values normalized by MAS5.0 and baseline transformed to a median target intensity. Txt file values for LGALS3 and LGALS1 (probe sets 208949_s_at and 201105_at) imported into Excel were manually extracted into Prism5.0.

Mice transgenic for the human P190 form of Bcr/Abl (Jackson Labs strain 017833) develop precursor B-lineage (pre-B) acute lymphoblastic leukemia, on average within 3 months of birth, when on a $\mathrm{C} 57 \mathrm{BI} / 6 \mathrm{~J}$ background. Bone marrows were isolated from control C57BLI/6J mice and from transgenic Bcr/Abl mice when they had not yet developed full-blown leukemia ( $<60$ days of age), from Bcr/Abl transgenic mice with overt leukemia and packed bone marrows (>90 days of age), and from fully leukemic mice that had received a seven-day treatment with $75 \mathrm{mg} / \mathrm{kg}$ AMN107 (nilotinib). Three mice were used per condition, and cells from each mouse were processed separately. Pre-B cells from these twelve bone marrows were flow-sorted using CD19 and AA4.1 as markers. Total RNA from CD19+ AA4.1+cells used for microarray analysis was isolated by RNeasy (QIAGEN) purification. Double-strand complementary DNA was generated from $5 \mu \mathrm{g}$ of total RNA using a poly(dT) oligonucleotide that contains a T7 RNA polymerase initiation site and the SuperScript III reverse transcription (Invitrogen). Biotinylated cRNA was generated and fragmented according to the Affymetrix protocol and hybridized to 430 mouse microarrays (Affymetrix). As described in Trageser et al (37), Cel files from GeneChip arrays were imported to the BRB Array Tool (http://linus.nci.nih.gov/BRB-ArrayTools.html) and processed using the RMA algorithm (Robust Multi-Array Average) for normalization and summarization. Data are available at https://www.ncbi.nlm.nih.gov/geo/query/acc.cgi?acc=GSE110104

\subsection{Drugs and reagents}

GM-CT-01 and GR-MD-02 were provided by Galectin Therapeutics, Inc (Norcross, Georgia, USA) and were stored at $4^{\circ} \mathrm{C}$. Nilotinib (AMN107) was obtained from Novartis (Basel, Switzerland). Nilotinib was dissolved in DMSO and stored at $-20^{\circ} \mathrm{C}$. A vincristine sulfate solution was obtained from Hospira Worldwide Inc. (Lake Forest, IL, USA). 


\subsection{Treatment with drugs, cell proliferation and viability, flow cytometry}

For proliferation assays, US7 or TXL2 cells were cultured in a 96-well plate at a density of $5 \times 10^{4} /$ well, in the presence of irradiated OP9 cells. Cells were treated with GM-CT-01 or with GR-MD-02, in combination with nilotinib or vincristine. Controls for nilotinib or vincristine were DMSO at the dilution matching the drug samples. After drug exposure, cells were collected and re-suspended in culture medium containing $0.1 \%$ (wt/vol) Trypan blue. Trypan blue-excluding and total cells were counted using a hemocytometer. All drug sensitivity assays were done in triplicate wells. Viability of the cells is expressed as the percentage of Trypan blue-excluding cells of the total number of cells. Data points show the mean $\pm S E M$ of triplicate samples.

To assay for the ability of GM-CT-01 to displace Galectin-3 using FACS, TXL2 cells were harvested from underneath the OP9 stromal layer. Cells were incubated with or without 20 $\mathrm{mg} / \mathrm{ml} \mathrm{GM}-\mathrm{CT}-01$ for $2 \mathrm{hrs}$ at $37^{\circ} \mathrm{C}$ in complete medium, then washed with PBS. DTSSP was added at $5 \mathrm{mM}$ to cross-link extracellular Galectin-3 to the cell surface. After a 30-min incubation at RT, the reaction was terminated by a 15-min incubation with $50 \mathrm{mM}$ glycine at $\mathrm{pH}$ 7.5. After a wash in PBS, cells were incubated with PE-Galectin-3 (Biolegend cat\# 126706) or matched isotype control for 15 mins and analyzed on BD Accuri C6 cytometer (BD Biosciences, San Jose, CA).

FACS analysis of mouse wt and dKO BP ALL cells used antibodies against AA4.1 (eBiosciences cat\#17-5892-82), CD43 (BD cat\#553270) and CD45/B220 (Biolegend cat\#103132). Gates were set based on isotype controls.

\subsection{Migration Assay}

For migration assays, human TXL2 or US7 cells $\left(1 \times 10^{5}\right)$ were seeded into the upper well of Transwell plates with a $5 \mu \mathrm{m}$ pore size. The lower chamber contained a layer of irradiated OP9 stromal cells with different concentrations of GR-MD-02 or GM-CT-01 as indicated. Wells without stromal cells in the bottom chamber served as controls. ALL cells migrated to the bottom wells were counted after overnight incubation. Migration of wt1, wt2, dKO1 and dKO2 BCP-ALL cells was measured individually, but values of wt1/wt2 and dKO1/dKO2 were combined for statistical analysis in Figure 4a.

\subsection{Cells}

Murine BCP leukemia: Murine leukemia cells were generated from bone marrows of age and sex matched wild-type (129 P3/J Lgals1 $\times$ Lgals $^{+/+}$) controls and Galectin-1/Galectin-3 (129 P3/J Lgals1 x Lgals3 ${ }^{-/}$) double knockout mice on a C57BI/6J background. Bone marrow cells were transduced with $\mathrm{P} 190 \mathrm{Bcr} / \mathrm{Abl}$-encoding retroviruses as previously described (18). In brief, transduced bone marrows were grown for 5 days with $10 \mathrm{ng} / \mathrm{ml}$ rmIL-7 and cultured in IMDM with $50 \mu \mathrm{M} \beta$-mercaptoethanol in 20\% FBS, $1 \%$ L-glutamine, $1 \%$ penicillin/streptomycin. The murine BCP-ALL cells were grown without stroma except where indicated. Stroma, when used, includes mouse embryonic fibroblasts (MEFs) or mitotically inactivated (irradiation or mitomycin treated) OP9 cells. All assays were performed within $\approx 6$ months of the initial transduction.

Cell lines and PDX-derived human BCP-ALLs: The murine OP9 stromal cell line (CRL-2749) and the human CML cell line K562 were obtained from the ATCC (Manassas, VA, USA). Human ALL cells including Ph-positive TXL2 and BLQ1, and Ph-negative US7 cells were described previously (17). Human leukemia cells were grown in MEM- $\alpha$ medium supplemented with $20 \%$ FBS, $1 \%$ L-glutamine and $1 \%$ penicillin/streptomycin (Invitrogen Corporation). Human ALL cells were cultured in the wells of a 6-well plate or a 96-well plate at a density of $0.5-1 \times 10^{6}$ cells $/ \mathrm{ml}$, in the presence of irradiated OP9 cells. 
Mouse embryonic fibroblasts (MEFs): E13.5 embryos were isolated from timed matings of C57Bl/6J mice. Internal organs and heads were removed and tissue homogenized by mincing with razor blades and pressure from the back of a syringe (72-74). Single cell suspensions were further generated by a $30-\mathrm{min}$ incubation at $37^{\circ} \mathrm{C}$ in $5 \mathrm{ml}$ Trypsin-EDTA. Tissue chunks were removed with a cell strainer, and cells were plated at a density of $6 \times 10^{6}$ per $15 \mathrm{~cm}$ dish in DMEM + 10\% FBS, P/S, and L-glutamine.

\subsection{Western blotting and immunoprecipitation}

Anti c-Abl Ab-3 antibodies for immunoprecipitation were from Calbiochem (San Diego $\mathrm{CA}$ ). For immunoprecipitations, $1 \mathrm{mg}$ of protein was used. Lysates were pre-cleared by incubation with $3 \mu \mathrm{g}$ rabbit or mouse IgG and PAA. ALL cells were lysed for 30 minutes on ice in RIPA buffer (50 mM Tris- $\mathrm{HCl}, \mathrm{pH} 8.0,150 \mathrm{mM} \mathrm{NaCl}, 1 \%$ Triton X-100, 0.5\% deoxycholate, $0.1 \%$ SDS, 5 mM EDTA) containing PMSF, aprotinin, leupeptin, pepstatin A, Na-fluoride and Na-orthovanadate. For detection of NF-kB (p100/52, p65), a nuclear extraction kit (Imgenex) was used to separate nuclear and cytoplasmic fractions. Cell extracts were subjected to $8-15 \%$ sodium dodecyl sulfate-polyacrylamide gel electrophoresis. Antibodies used include pY20 (BD-Transduction San Jose CA), Galectin-3 (Biolegend, San Diego, USA), phospho-ERK1/2, phospho-p38, phospho-STAT5, phospho-AKT, AKT, (Cell Signaling Technology, USA), ERK1/2, NF-kB p65, Bcr N-20 (Santa Cruz Biotechnology, USA), NF-kB p100/52 (Millipore, USA) using standard procedures. Gapdh (Chemicon International, USA) or $\beta$-actin (Sigma, USA) antibodies were used as a loading control. The phospho-SFK (Y416, Cell Signaling Technology) antibody recognizes pY416 in Src but may cross-react with other Src family members (Lyn, Fyn, Lck, Yes and Hck) when phosphorylated at equivalent sites.

\subsection{Statistical analysis}

Multiple $t$ tests were performed for group analysis. A False Discovery Rate approach was adopted to decide the significance of the comparison based on that no more than $5 \%$ of the discoveries will be false discoveries. Pearson correlation analysis was performed to examine expression correlations between LGALS1 and LGALS3 genes in public data sets. A two-tailed $p$-value was calculated to suggest the significance of the correlation and a p-value $<0.05$ was used to decide whether the two sets of expression values were correlated.

Acknowledgments: We very gratefully acknowledge Francoise Poirier for the wt and Lgals1 $x$ Lgals3 -/- bone marrow samples, without which this study would not have been possible. We also thank Peter Traber and Anatole A. Klyosov (Galectin Therapeutics, Newton, Massachusetts 02459) for providing GM-CT-01 and GR-MD-02, and Ravia Salgia for the generous gift of the 3F12 anti-Abl monoclonal antibodies. This study was supported by PHS NIH RO1 CA172040 and CA090321 (to NH).

$\begin{array}{ll}\text { Abbreviations } \\ \text { BCP-ALL } & \text { B-cell precursor acute lymphoblastic leukemia } \\ \text { CML } & \text { chronic myelogenous leukemia } \\ \text { dKO } & \text { double knockout } \\ \text { DTSSP } & \left(3,3^{\prime} \text {-dithiobis(sulfosuccinimidyl propionate)) }\right. \\ \text { MEF } & \text { mouse embryonic fibroblast } \\ \text { MFI } & \text { mean fluorescent intensity } \\ \text { Ph-positive } & \text { Philadelphia chromosome positive } \\ \text { PDX } & \text { patient-derived xenograft } \\ \text { Ph-negative } & \text { Philadelphia chromosome negative } \\ \text { SFK } & \text { Src family kinase } \\ \text { WB } & \text { Western blot } \\ \text { wt } & \text { Wild type }\end{array}$




\section{Literature cited}

1. Malouf C, Ottersbach K. Molecular processes involved in B cell acute lymphoblastic leukaemia. Cellular and molecular life sciences : CMLS. 2018;75(3):417-46.

2. Lilljebjorn $\mathrm{H}$, Fioretos $\mathrm{T}$. New oncogenic subtypes in pediatric B-cell precursor acute lymphoblastic leukemia. Blood. 2017;130(12):1395-401.

3. Mullighan CG. Molecular genetics of B-precursor acute lymphoblastic leukemia. The Journal of clinical investigation. 2012;122(10):3407-15.

4. Gu Z, Churchman ML, Roberts KG, Moore I, Zhou X, Nakitandwe J, et al. PAX5-driven subtypes of B-progenitor acute lymphoblastic leukemia. Nat Genet. 2019;51(2):296-307.

5. Hermans A, Heisterkamp N, von Linden M, van Baal S, Meijer D, van der Plas D, et al. Unique fusion of bcr and c-abl genes in Philadelphia chromosome positive acute lymphoblastic leukemia. Cell. 1987;51(1):33-40.

6. Cortes JE, Kim DW, Pinilla-Ibarz J, le Coutre P, Paquette R, Chuah C, et al. A phase 2 trial of ponatinib in Philadelphia chromosome-positive leukemias. The New England journal of medicine. 2013;369(19):1783-96.

7. Heisterkamp N, Jenster G, ten Hoeve J, Zovich D, Pattengale PK, Groffen J. Acute leukaemia in bcr/abl transgenic mice. Nature. 1990;344(6263):251-3.

8. Van Etten RA. Retroviral transduction models of Ph+ leukemia: advantages and limitations for modeling human hematological malignancies in mice. Blood cells, molecules \& diseases. 2001;27(1):201-5.

9. Sundaresh A, Williams O. Mechanism of ETV6-RUNX1 Leukemia. Advances in experimental medicine and biology. 2017;962:201-16.

10. Meyer C, Burmeister T, Groger D, Tsaur G, Fechina L, Renneville A, et al. The MLL recombinome of acute leukemias in 2017. Leukemia. 2017; 32:273-284.

11. Tallen G, Ratei R, Mann G, Kaspers G, Niggli F, Karachunsky A, et al. Long-term outcome in children with relapsed acute lymphoblastic leukemia after time-point and site-of-relapse stratification and intensified short-course multidrug chemotherapy: results of trial ALL-REZ BFM 90. Journal of clinical oncology : official journal of the American Society of Clinical Oncology. 2010;28(14):2339-47.

12. Meads MB, Gatenby RA, Dalton WS. Environment-mediated drug resistance: a major contributor to minimal residual disease. Nat Rev Cancer. 2009;9(9):665-74.

13. Meads MB, Hazlehurst LA, Dalton WS. The bone marrow microenvironment as a tumor sanctuary and contributor to drug resistance. Clinical cancer research : an official journal of the American Association for Cancer Research. 2008;14(9):2519-26.

14. Parameswaran R, Lim M, Arutyunyan A, Abdel-Azim H, Hurtz C, Lau K, et al. $\mathrm{O}$-acetylated $\mathrm{N}$-acetylneuraminic acid as a novel target for therapy in human pre-B acute lymphoblastic leukemia. J Exp Med. 2013;210(4):805-19.

15. Hsieh YT, Gang EJ, Geng H, Park E, Huantes S, Chudziak D, et al. Integrin alpha4 blockade sensitizes drug resistant pre-B acute lymphoblastic leukemia to chemotherapy. Blood. 2013;121(10):1814-8.

16. Arutyunyan A, Stoddart S, Yi SJ, Fei F, Lim M, Groffen P, et al. Expression of cassini, a murine gamma-satellite sequence conserved in evolution, is regulated in normal and malignant hematopoietic cells. BMC genomics. 2012;13:418. 
17. Fei F, Lim M, Schmidhuber S, Moll J, Groffen J, Heisterkamp N. Treatment of human pre-B acute lymphoblastic leukemia with the Aurora kinase inhibitor PHA-739358 (Danusertib). Molecular cancer. 2012;11:42.

18. Duy C, Hurtz C, Shojaee S, Cerchietti L, Geng H, Swaminathan S, et al. BCL6 enables $\mathrm{Ph}+$ acute lymphoblastic leukaemia cells to survive BCR-ABL1 kinase inhibition. Nature. 2011;473(7347):384-8.

19. Parameswaran R, Yu M, Lim M, Groffen J, Heisterkamp N. Combination of drug therapy in acute lymphoblastic leukemia with a CXCR4 antagonist. Leukemia. 2011;25(8):1314-23.

20. Sison EA, Brown P. The bone marrow microenvironment and leukemia: biology and therapeutic targeting. Expert review of hematology. 2011;4(3):271-83.

21. Tavor S, Petit I. Can inhibition of the SDF-1/CXCR4 axis eradicate acute leukemia? Seminars in cancer biology. 2010;20(3):178-85.

22. Elola MT, Blidner AG, Ferragut F, Bracalente C, Rabinovich GA. Assembly, organization and regulation of cell-surface receptors by lectin-glycan complexes. The Biochemical journal. 2015;469(1):1-16.

23. Garner OB, Baum LG. Galectin-glycan lattices regulate cell-surface glycoprotein organization and signalling. Biochemical Society transactions. 2008;36(Pt 6):1472-7.

24. Fei F, Joo EJ, Tarighat SS, Schiffer I, Paz H, Fabbri M, et al. B-cell precursor acute lymphoblastic leukemia and stromal cells communicate through Galectin-3. Oncotarget. 2015;6(13):11378-94.

25. Juszczynski P, Rodig SJ, Ouyang J, O'Donnell E, Takeyama K, Mlynarski W, et al. MLL-rearranged $B$ lymphoblastic leukemias selectively express the immunoregulatory carbohydrate-binding protein galectin-1. Clinical cancer research : an official journal of the American Association for Cancer Research. 2010;16(7):2122-30.

26. Paz H, Joo EJ, Chou CH, Fei F, Mayo KH, Abdel-Azim H, et al. Treatment of B-cell precursor acute lymphoblastic leukemia with the Galectin-1 inhibitor PTX008. J Exp Clin Cancer Res. 2018;37(1):67.

27. Bonzi J, Bornet O, Betzi S, Kasper BT, Mahal LK, Mancini SJ, et al. Pre-B cell receptor binding to galectin-1 modifies galectin-1/carbohydrate affinity to modulate specific galectin-1/glycan lattice interactions. Nature communications. 2015;6:6194.

28. Mourcin F, Breton C, Tellier J, Narang P, Chasson L, Jorquera A, et al. Galectin-1-expressing stromal cells constitute a specific niche for pre-Bll cell development in mouse bone marrow. Blood. 2011;117(24):6552-61.

29. Reesink HL, Sutton RM, Shurer CR, Peterson RP, Tan JS, Su J, et al. Galectin-1 and galectin-3 expression in equine mesenchymal stromal cells (MSCs), synovial fibroblasts and chondrocytes, and the effect of inflammation on MSC motility. Stem cell research \& therapy. 2017;8(1):243.

30. Chan YC, Lin HY, Tu Z, Kuo YH, Hsu SD, Lin CH. Dissecting the Structure-Activity Relationship of Galectin-Ligand Interactions. International journal of molecular sciences. 2018;19(2).

31. Mackinnon AC, Gibbons MA, Farnworth SL, Leffler H, Nilsson UJ, Delaine T, et al. Regulation of transforming growth factor-beta1-driven lung fibrosis by galectin-3. American journal of respiratory and critical care medicine. 2012;185(5):537-46. 
32. Miller MC, Ippel H, Suylen D, Klyosov AA, Traber PG, Hackeng T, et al. Binding of polysaccharides to human galectin-3 at a noncanonical site in its carbohydrate recognition domain. Glycobiology. 2016;26(1):88-99.

33. Miller MC, Klyosov A, Mayo KH. The alpha-galactomannan Davanat binds galectin-1 at a site different from the conventional galectin carbohydrate binding domain. Glycobiology. 2009;19(9):1034-45.

34. Miller MC, Klyosov AA, Mayo KH. Structural features for alpha-galactomannan binding to galectin-1. Glycobiology. 2012;22(4):543-51.

35. Traber PG, Chou H, Zomer E, Hong F, Klyosov A, Fiel MI, et al. Regression of fibrosis and reversal of cirrhosis in rats by galectin inhibitors in thioacetamide-induced liver disease. PloS one. 2013;8(10):e75361.

36. Feldhahn N, Arutyunyan A, Stoddart S, Zhang B, Schmidhuber S, Yi SJ, et al. Environment-mediated drug resistance in Bcr/Abl-positive acute lymphoblastic leukemia. Oncoimmunology. 2012;1(5):618-29.

37. Trageser D, lacobucci I, Nahar R, Duy C, von Levetzow G, Klemm L, et al. Pre-B cell receptor-mediated cell cycle arrest in Philadelphia chromosome-positive acute lymphoblastic leukemia requires IKAROS function. J Exp Med. 2009;206(8):1739-53.

38. Fei F, Abdel-Azim H, Lim M, Arutyunyan A, von Itzstein M, Groffen J, et al. Galectin-3 in pre-B acute lymphoblastic leukemia. Leukemia. 2013;27(12):2385-8.

39. Yu M, Gang EJ, Parameswaran R, Stoddart S, Fei F, Schmidhuber S, et al. AMD3100 sensitizes acute lymphoblastic leukemia cells to chemotherapy in vivo. Blood Cancer J. 2011;1(4):e14.

40. Tang DD, Gerlach BD. The roles and regulation of the actin cytoskeleton, intermediate filaments and microtubules in smooth muscle cell migration. Respiratory research. 2017;18(1):54.

41. Preisinger $\mathrm{C}$, Kolch $\mathrm{W}$. The Bcr-Abl kinase regulates the actin cytoskeleton via a GADS/SIp-76/Nck1 adaptor protein pathway. Cellular signalling. 2010;22(5):848-56.

42. Salgia R, Quackenbush E, Lin J, Souchkova N, Sattler M, Ewaniuk DS, et al. The $\mathrm{BCR} / \mathrm{ABL}$ oncogene alters the chemotactic response to stromal-derived factor-1alpha. Blood. 1999;94(12):4233-46.

43. Balan $V$, Nangia-Makker $P$, Kho DH, Wang Y, Raz A. Tyrosine-phosphorylated galectin-3 protein is resistant to prostate-specific antigen (PSA) cleavage. The Journal of biological chemistry. 2012;287(8):5192-8.

44. Balan V, Nangia-Makker P, Jung YS, Wang Y, Raz A. Galectin-3: A novel substrate for c-Abl kinase. Biochimica et biophysica acta. 2010;1803(10):1198-205.

45. Li X, Ma Q, Wang J, Liu X, Yang Y, Zhao H, et al. c-Abl and Arg tyrosine kinases regulate lysosomal degradation of the oncoprotein Galectin-3. Cell death and differentiation. 2010;17(8):1277-87.

46. Grosveld G, Verwoerd T, van Agthoven T, de Klein A, Ramachandran KL, Heisterkamp $\mathrm{N}$, et al. The chronic myelocytic cell line K562 contains a breakpoint in bcr and produces a chimeric bcr/c-abl transcript. Molecular and cellular biology. 1986;6(2):607-16.

47. Yamamoto-Sugitani M, Kuroda J, Ashihara E, Nagoshi H, Kobayashi T, Matsumoto Y, et al. Galectin-3 (Gal-3) induced by leukemia microenvironment promotes drug resistance and bone marrow lodgment in chronic myelogenous leukemia. Proc Natl Acad Sci U S A. 2011;108(42):17468-73. 
48. ten Hoeve J, Kaartinen V, Fioretos T, Haataja L, Voncken JW, Heisterkamp N, et al. Cellular interactions of CRKL, and SH2-SH3 adaptor protein. Cancer Res. 1994;54(10):2563-7.

49. Mallampati S, Leng X, Ma H, Zeng J, Li J, Wang H, et al. Tyrosine kinase inhibitors induce mesenchymal stem cell-mediated resistance in BCR-ABL+ acute lymphoblastic leukemia. Blood. 2015;125(19):2968-73.

50. Sirko S, Irmler M, Gascon S, Bek S, Schneider S, Dimou L, et al. Astrocyte reactivity after brain injury-: The role of galectins 1 and 3. Glia. 2015;63(12):2340-61.

51. Aits S, Kricker J, Liu B, Ellegaard AM, Hamalisto S, Tvingsholm S, et al. Sensitive detection of lysosomal membrane permeabilization by lysosomal galectin puncta assay. Autophagy. 2015;11(8):1408-24.

52. Delaine T, Collins P, MacKinnon A, Sharma G, Stegmayr J, Rajput VK, et al. Galectin-3-Binding Glycomimetics that Strongly Reduce Bleomycin-Induced Lung Fibrosis and Modulate Intracellular Glycan Recognition. Chembiochem : a European journal of chemical biology. 2016;17(18):1759-70.

53. Saint-Lu N, Oortwijn BD, Pegon JN, Odouard S, Christophe OD, de Groot PG, et al. Identification of galectin-1 and galectin-3 as novel partners for von Willebrand factor. Arteriosclerosis, thrombosis, and vascular biology. 2012;32(4):894-901.

54. $\mathrm{Yu} X$, Siegel R, Roeder RG. Interaction of the B cell-specific transcriptional coactivator OCA-B and galectin-1 and a possible role in regulating BCR-mediated B cell proliferation. The Journal of biological chemistry. 2006;281(22):15505-16.

55. Clark AG, Weston ML, Foster MH. Lack of galectin-1 or galectin-3 alters $B$ cell deletion and anergy in an autoantibody transgene model. Glycobiology. 2013;23(7):893-903.

56. Levy R, Biran A, Poirier F, Raz A, Kloog Y. Galectin-3 mediates cross-talk between K-Ras and Let-7c tumor suppressor microRNA. PloS one. 2011;6(11):e27490.

57. Saunders $A E$, Johnson $P$. Modulation of immune cell signalling by the leukocyte common tyrosine phosphatase, CD45. Cellular signalling. 2010;22(3):339-48.

58. Wong NK, Lai JC, Birkenhead D, Shaw AS, Johnson P. CD45 down-regulates Lck-mediated CD44 signaling and modulates actin rearrangement in T cells. J Immunol. 2008;181(10):7033-43.

59. Grigorian A, Torossian S, Demetriou M. T-cell growth, cell surface organization, and the galectin-glycoprotein lattice. Immunol Rev. 2009;230(1):232-46.

60. Walzel H, Schulz U, Neels P, Brock J. Galectin-1, a natural ligand for the receptor-type protein tyrosine phosphatase CD45. Immunol Lett. 1999;67(3):193-202.

61. Streetly MJ, Maharaj L, Joel S, Schey SA, Gribben JG, Cotter FE. GCS-100, a novel galectin-3 antagonist, modulates MCL-1, NOXA, and cell cycle to induce myeloma cell death. Blood. 2010;115(19):3939-48.

62. Chauhan D, Li G, Podar K, Hideshima T, Neri P, He D, et al. A novel carbohydrate-based therapeutic GCS-100 overcomes bortezomib resistance and enhances dexamethasone-induced apoptosis in multiple myeloma cells. Cancer Res. 2005;65(18):8350-8.

63. Arsenijevic A, Milovanovic J, Stojanovic B, Djordjevic D, Stanojevic I, Jankovic N, et al. Gal-3 Deficiency Suppresses Novosphyngobium aromaticivorans Inflammasome Activation and IL-17 Driven Autoimmune Cholangitis in Mice. Front Immunol. 2019;10:1309. 
64. Curti BD, Koguchi Y, Leidner RS, Rolig AS, Sturgill ER, Sun Z, et al. Enhancing clinical and immunological effects of anti-PD-1 with belapectin, a galectin-3 inhibitor. J Immunother Cancer. 2021;9(4).

65. Sturgill ER, Rolig AS, Linch SN, Mick C, Kasiewicz MJ, Sun Z, et al. Galectin-3 inhibition with belapectin combined with anti-OX40 therapy reprograms the tumor microenvironment to favor anti-tumor immunity. Oncoimmunology. 2021;10(1):1892265.

66. Al Attar A, Antaramian A, Noureddin M. Review of galectin-3 inhibitors in the treatment of nonalcoholic steatohepatitis. Expert Rev Clin Pharmacol. 2021;14(4):457-64.

67. Chalasani N, Abdelmalek MF, Garcia-Tsao G, Vuppalanchi R, Alkhouri N, Rinella M, et al. Effects of Belapectin, an Inhibitor of Galectin-3, in Patients With Nonalcoholic Steatohepatitis With Cirrhosis and Portal Hypertension. Gastroenterology. 2020;158(5):1334-45 e5.

68. Stegmayr J, Lepur A, Kahl-Knutson B, Aguilar-Moncayo M, Klyosov AA, Field RA, et al. Low or No Inhibitory Potency of the Canonical Galectin Carbohydrate-binding Site by Pectins and Galactomannans. The Journal of biological chemistry. 2016;291(25):13318-34.

69. Stasenko M, Smith E, Yeku O, Park KJ, Laster I, Lee K, et al. Targeting galectin-3 with a high-affinity antibody for inhibition of high-grade serous ovarian cancer and other MUC16/CA-125-expressing malignancies. Sci Rep. 2021;11(1):3718.

70. Coustan-Smith E, Song G, Clark C, Key L, Liu P, Mehrpooya M, et al. New markers for minimal residual disease detection in acute lymphoblastic leukemia. Blood. 2011;117(23):6267-76.

71. Hirabayashi S, Ohki K, Nakabayashi K, Ichikawa H, Momozawa Y, Okamura K, et al. ZNF384-related fusion genes define a subgroup of childhood B-cell precursor acute lymphoblastic leukemia with a characteristic immunotype. Haematologica. 2017;102(1):118-29.

72. Dong S, Maziveyi M, Alahari SK. Primary Tumor and MEF Cell Isolation to Study Lung Metastasis. Journal of visualized experiments : JoVE. 2015(99):e52609.

73. Jozefczuk J, Drews K, Adjaye J. Preparation of mouse embryonic fibroblast cells suitable for culturing human embryonic and induced pluripotent stem cells. Journal of visualized experiments : JoVE. 2012(64).

74. Michalska E. Isolation and propagation of mouse embryonic fibroblasts and preparation of mouse embryonic feeder layer cells. Current protocols in stem cell biology. 2007; Chapter 1:Unit1C 3. 


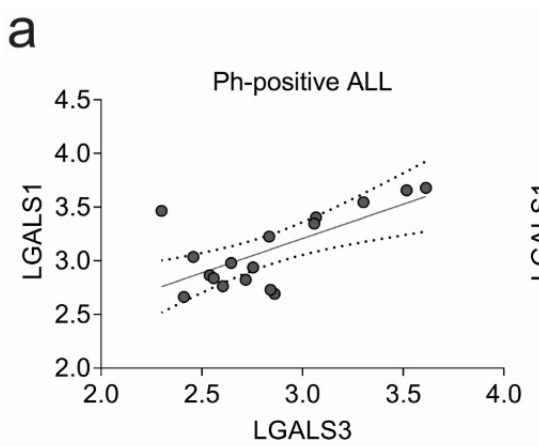

b
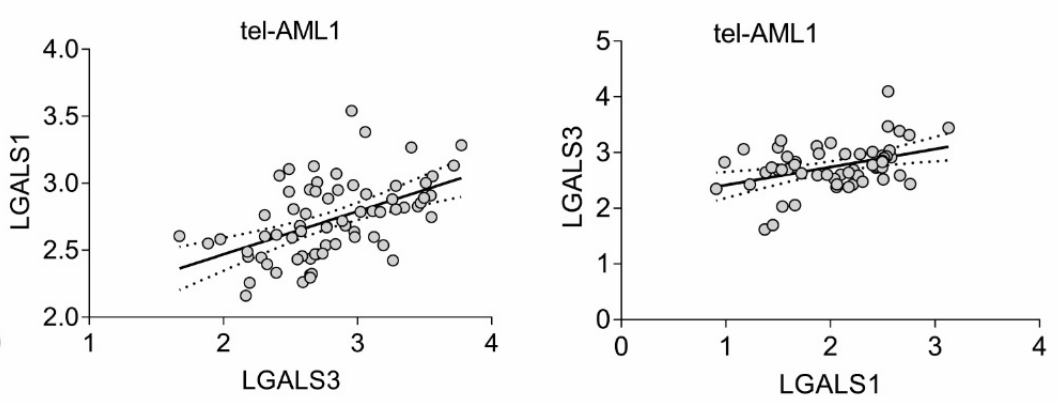

C
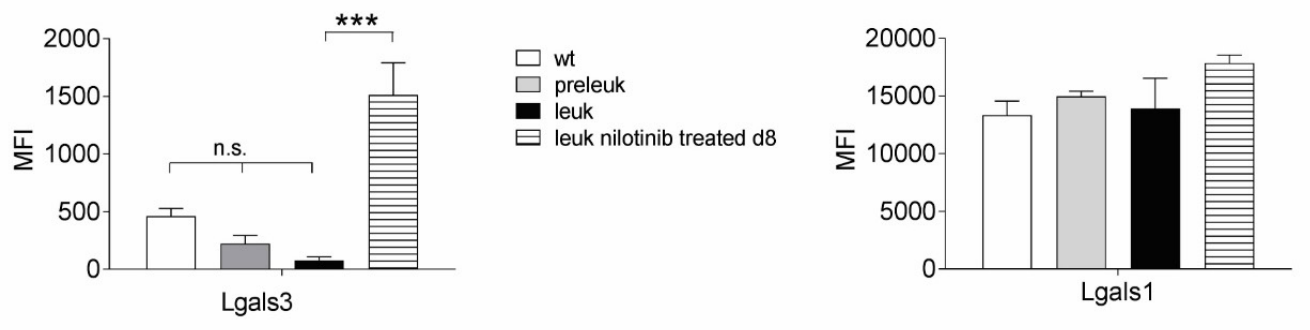

Figure 1. Gene expression of Galectin-1 and Galectin-3 in Bcr-Abl expressing ALL cells.

Positive correlation between log10 Galectin-1 and Galectin-3 mRNA expression in (a) human Ph-positive ALL samples and (b) tel-AML1 ALL samples in two different arrays. Dotted lines indicate 95\% confidence range of best fit line. (c) Meta-analysis of GSE110104 for Galectin-3 (Lgals3) and Galectin-1 (Lgals1) gene expression in mouse B-cell precursor cells, flow sorted from bone marrows of control wild type (wt) mice and pre-leukemic, fully leukemic (leuk), and leukemic, $75 \mathrm{mg} / \mathrm{kg} / \mathrm{d}$ d 8 nilotinib-treated $B C R / A B L \mathrm{P} 190$ transgenic mice. Each set consists of three biological replicates. ${ }^{* *} p<0.001$. Tukey's multiple comparisons test. Right panel, no significant differences. MFI, mean fluorescent intensity. 
a

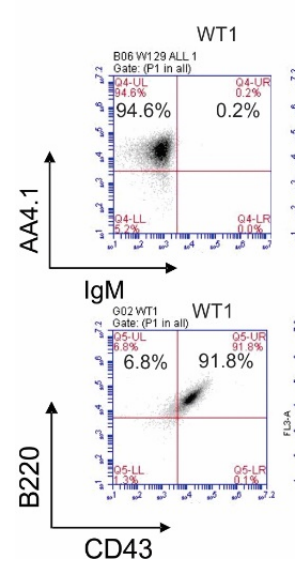

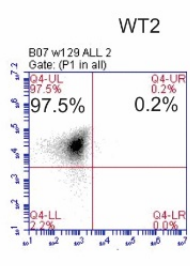

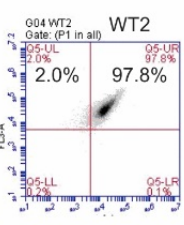

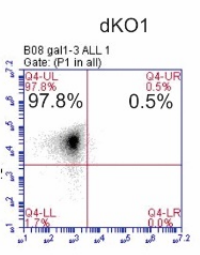

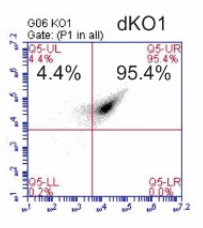

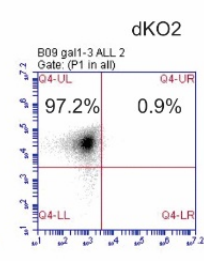

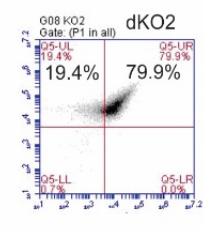

b

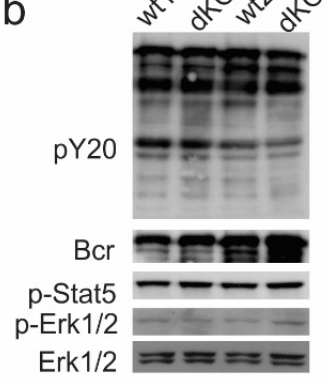

C

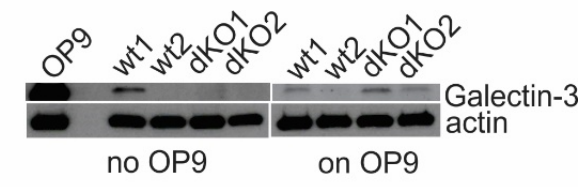

Figure 2. Characterization of murine Bcr/Abl-positive BCP-ALL cells lacking Galectin-1 and Galectin-3 generated by transformation of Lgals1 $x$ Lgals3 -/- or matched WT bone marrow cells with p190 Bcr/Abl. Samples include wild type (wt) pre-B ALL \#1 and \#2, and Lgals3xLgals1-/- (dKO) pre-B ALLs dKO1 and dKO2, representing independent transductions. (a) FACS analysis for the indicated markers at week 3 after transduction. Gates were set using isotype controls. Numbers: \% cells in indicated quadrants. (b, c) Western blot analysis with the antibodies indicated to the side of the panels. The ratio of $\mathrm{pSrc/Src}$ was determined by densitometric scanning of Western blot film images using Image J software. Gapdh, loading control. BCP-ALL cells grown without stroma. (c) Cells as in (b) grown alone, or co-cultured for 24 hours with mitomycin-C inactivated murine OP9 bone-marrow stromal cells as a source of Galectin-3.

Figure 3. -next page- Murine Bcr/Abl-positive BCP-ALL cells lacking Galectin-1 and Galectin-3 have reduced growth and survival. (a) Proliferation as measured by viable cell counts of the indicated genotypes. Left panel, 7 weeks after transduction; right panel, 8 weeks after transduction. ${ }^{* * *} p<0.001$ for the indicated group comparisons. (b-d) Comparative analysis of viability (left panels) and proliferation (right panels) of dKO and wt ALL cells in a long-term drug treatment (b) Cells treated with vincristine. Values for dKO $8 \mathrm{nM}$ vincristine compared to wt $+8 \mathrm{nM}$ vincristine: ${ }^{*} p<0.05$, ${ }^{* *} p<0.01{ }^{* * *}, p<0.001$. (c, d). Nilotinib treatment. Experiments with wt and dKO cells grouped in panels $\mathbf{c}$ and $\mathbf{d}$ were performed together but are shown in separate graphs for clarity. Cells at each time point grown without and with MEFs while treated with nilotinib are compared pair-wise at each time point for statistically significant differences. Significant differences are indicated. ${ }^{*} p<0.05,{ }^{* *} p<0.01{ }^{* * *}, p<0.001$ 
a

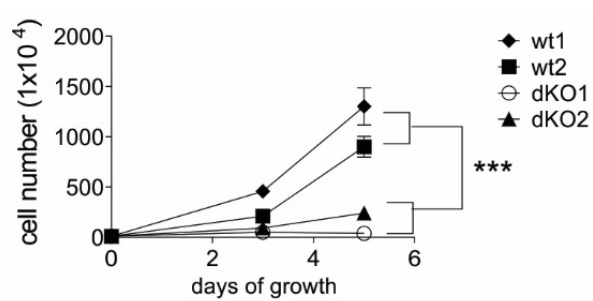

b
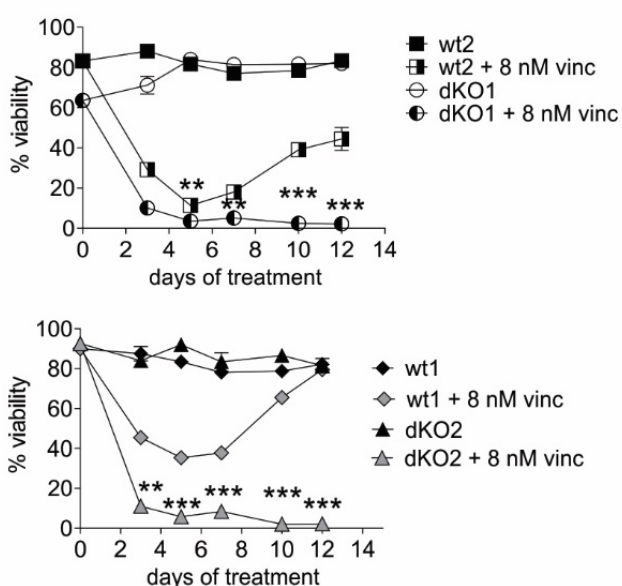

C
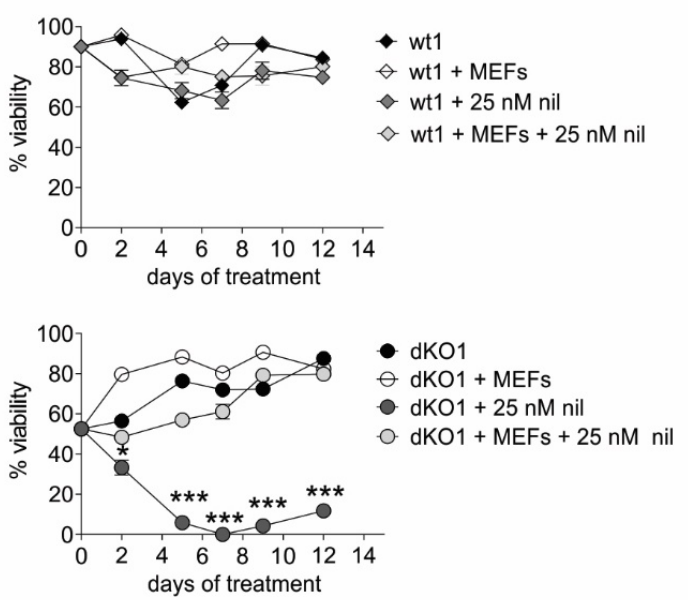

d

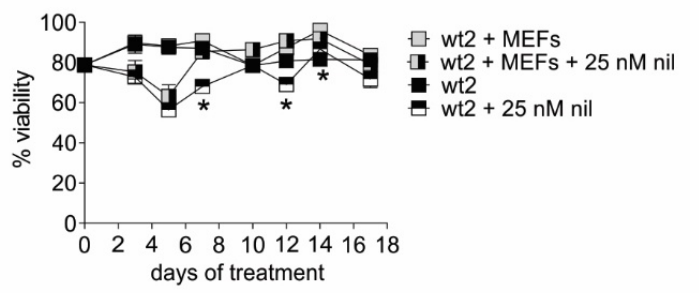

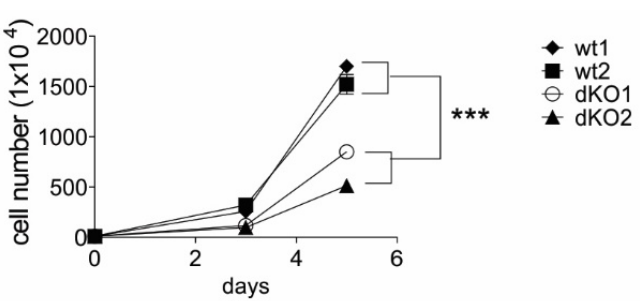
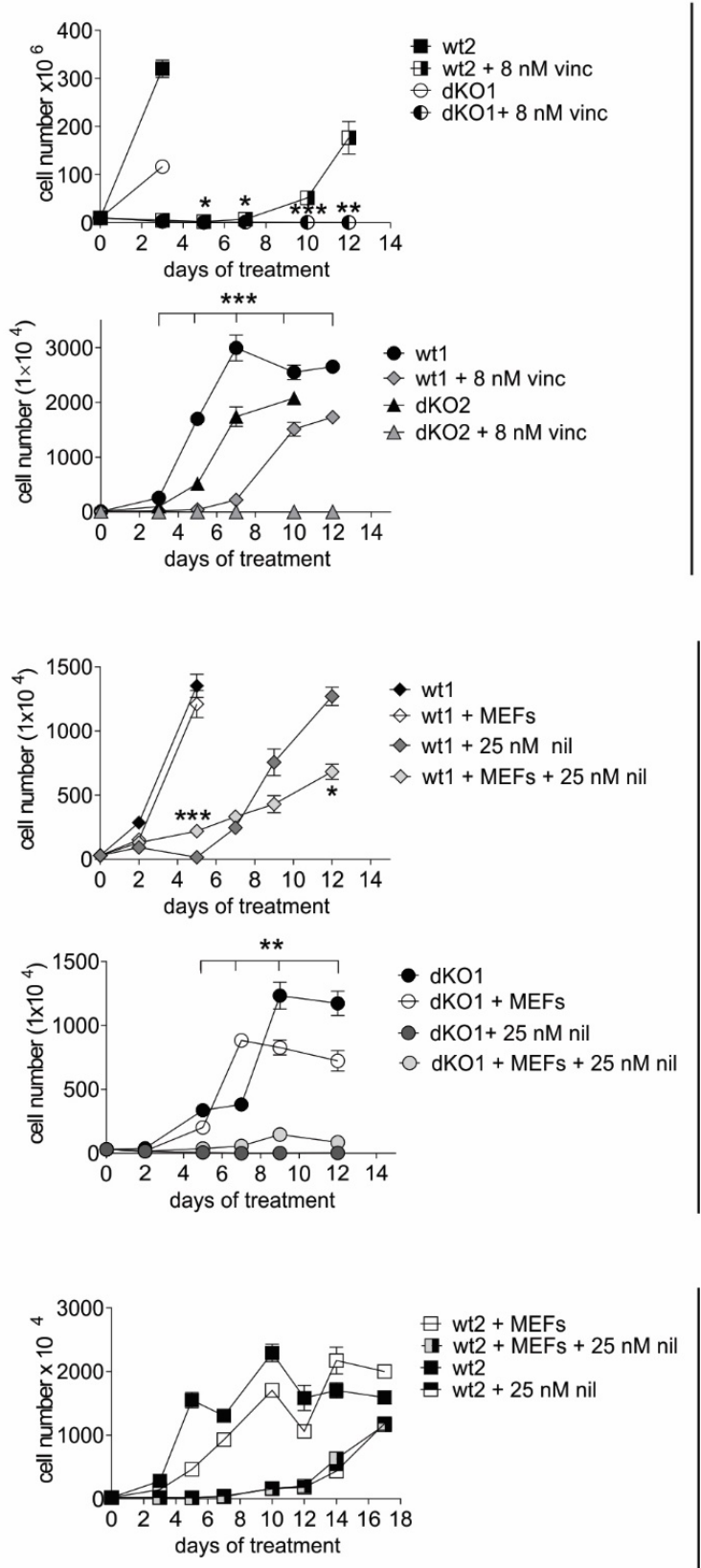

$\boxminus w t 2+$ MEFs

wt2 + MEFs + $25 \mathrm{nM}$ nil

wt2

wt2 + $25 \mathrm{nM}$ nil

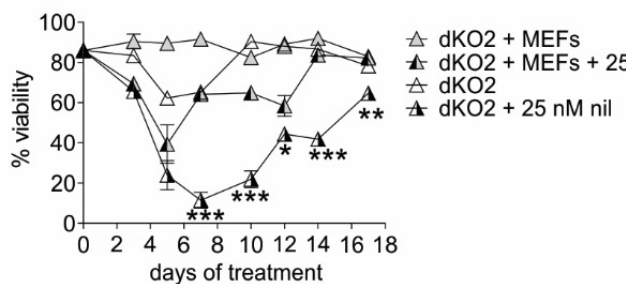

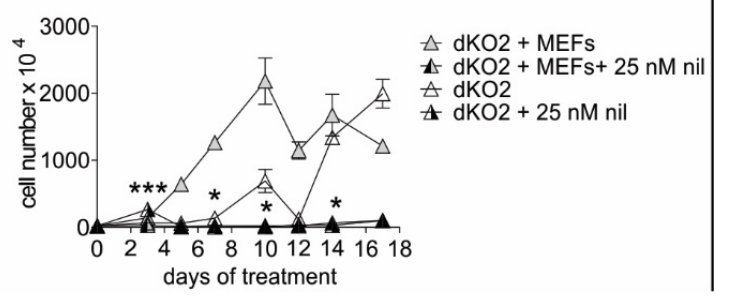




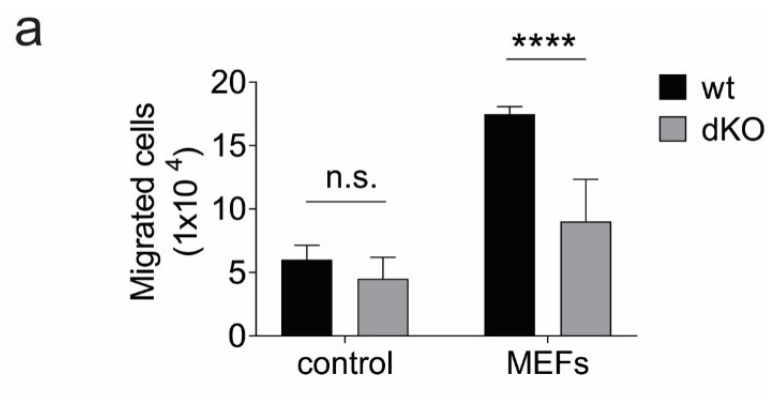

b

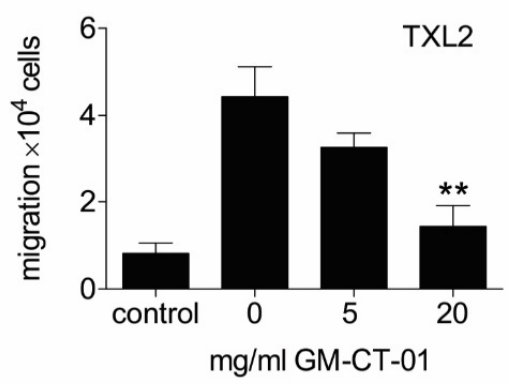

$\mathrm{d}$

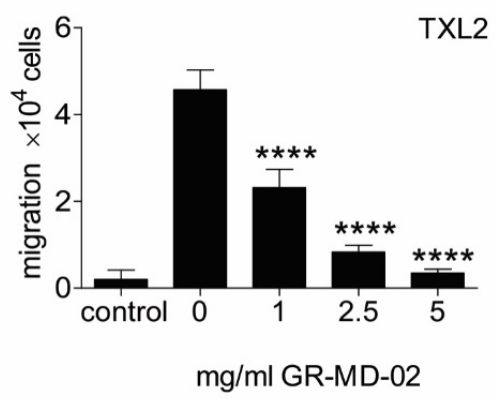

C

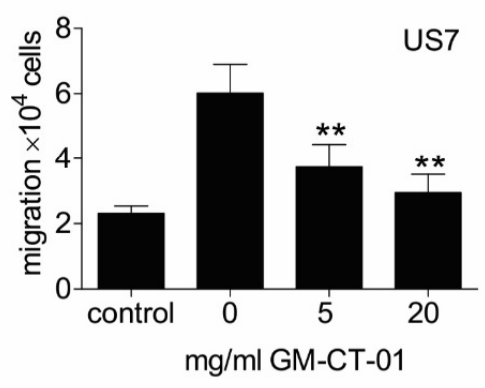

e

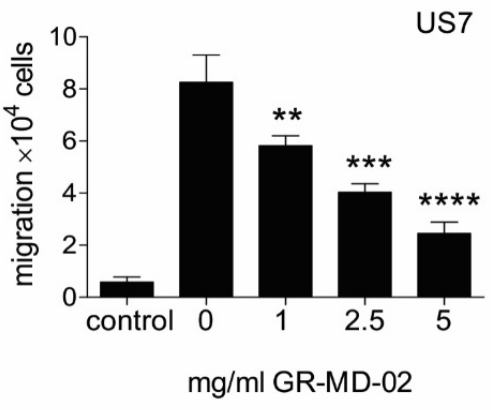

Figure 4. Migration of ALL cells to stroma is promoted by Galectin-1 / Galectin-3. (a) mouse BCP-ALL wt1 / wt2 and dKO1 / dKO2 cells were plated in the upper wells of a Transwell and allowed to migrate overnight towards control medium or MEFs plated in the bottom well.

${ }^{* * * *} p<0.001$ for differences between combined wt and dKO samples, unpaired t-test. Control samples, not significant. (b-e) Overnight migration of human BCP-ALL TXL2 (Ph-positive) or US7 (Ph-chromosome negative) to OP9 stromal cells plated in the bottom of Transwells in the absence or presence of the indicated concentrations of GM-CT-01 (b, c) or GR-MD-02 $(\mathbf{d}, \mathbf{e})$. For b-e, ${ }^{*} p<0.05,{ }^{* *} p<0.01,{ }^{* * *} p<0.001,{ }^{* * * *} p<0.0001$, one-way ANOVA, between 0 $\mathrm{mg} / \mathrm{ml}$ compound and samples incubated with the indicated amounts of compound.

Controls: only medium, no OP9 cells in bottom well. 


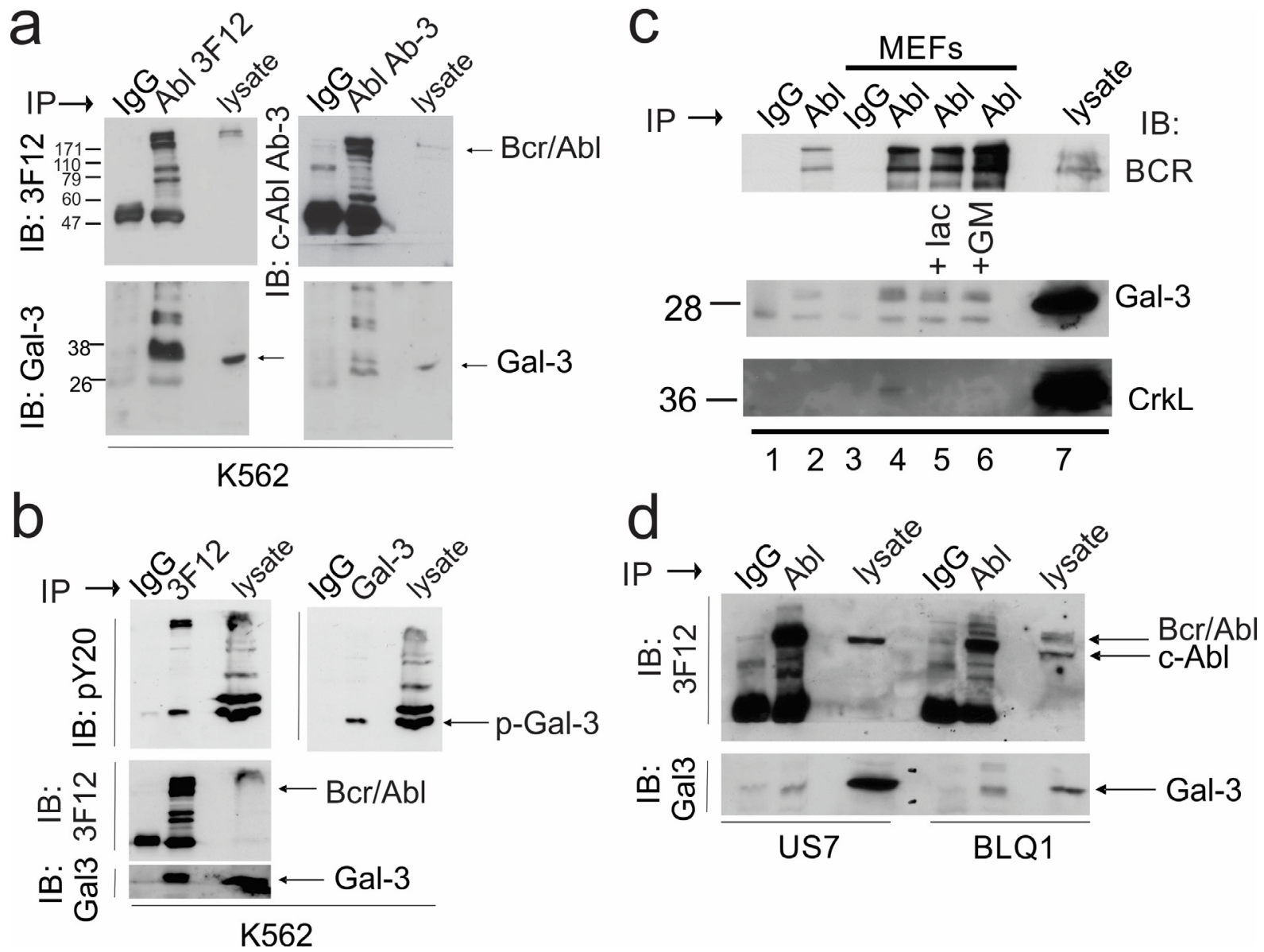

Figure 5. Complex formation of Galectin-3 with (Bcr/)Abl in leukemia cells. Lysates made from (a-c) the CML cell line K562 or (d) BCP-ALLs. (a). Immunoprecipitation with control Ig or two different anti-c-Abl antibodies: 3F12 or c-Abl Ab-3 (Calbiochem) as indicated above the lanes. Antibodies used for immunoblotting are indicated to the left. Arrows to the right of the panels point to the location of Bcr/Abl and Galectin-3 (Gal-3). Note: the right upper panel was exposed longer than the left upper panel. (b). Immunoprecipitation with anti-Abl 3F12 or Galectin-3 antibodies followed by immunoblotting with the antibodies indicated to the left of the panels. (c) Immunoprecipitation from K562 lysates of cells grown as suspension culture (lanes 1-2) or on MEFs (lanes 3-6) as indicated above the panel. Lane 7, total cell lysate. Antibodies used for IP include control IgG (lanes 1 and 3) or 3F12 anti-Abl (lane 2, lanes 4-6). Lane 5, cells treated for 2 hours with $50 \mathrm{mM}$ lactose; lane 6, cells treated with $10 \mathrm{mg} / \mathrm{ml}$ GM-CT-01 for 2 hours. After immunoblotting with Galectin-3, the panel was stripped and re-probed with anti-Crkl antibodies. A $12 \%$ SDS-PAA gel was used to obtain separation in the lower molecular weight range. (d) Immunoprecipitation of c-Abl and Bcr/Abl from lysates of human BCP-ALL US7 (Ph-negative) and BLQ1 (Ph-positive). Cells were grown on OP9 stroma before preparation of lysates. 
a

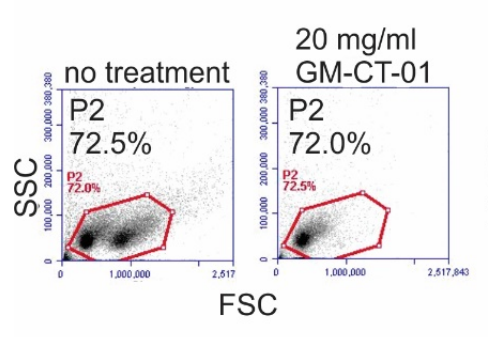

d

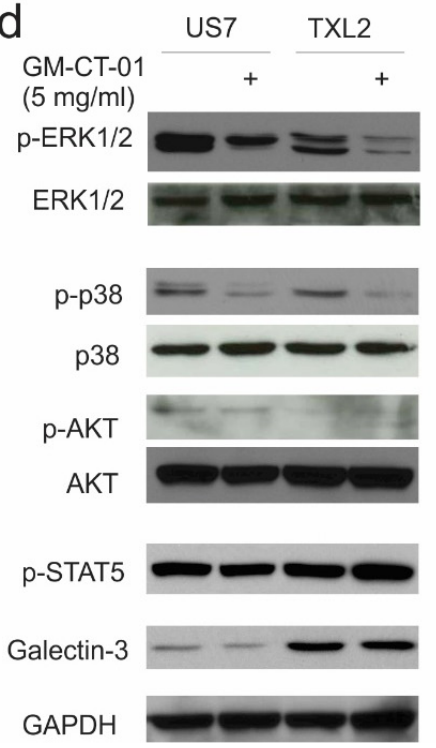

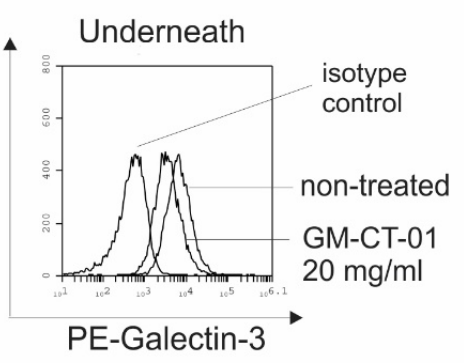

e

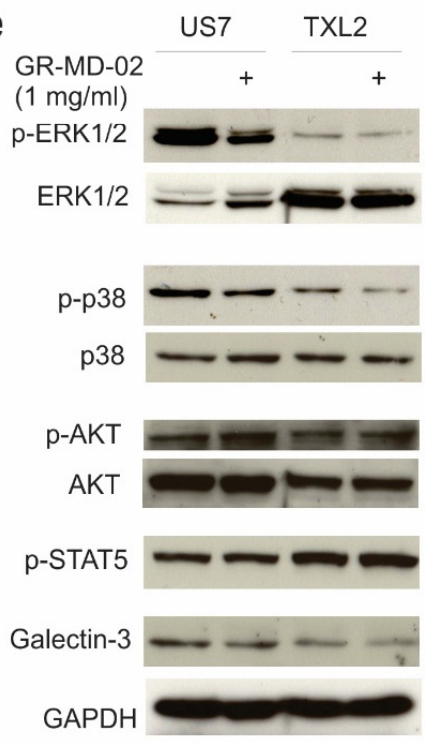

b

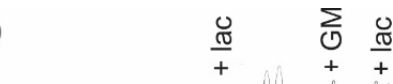

Galectin-3 actin

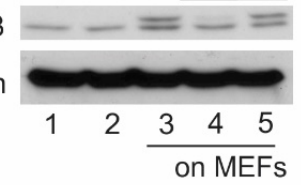

C

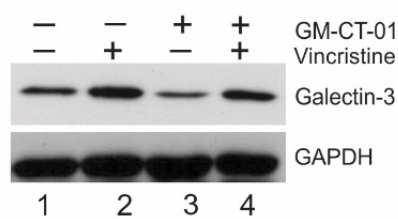

f

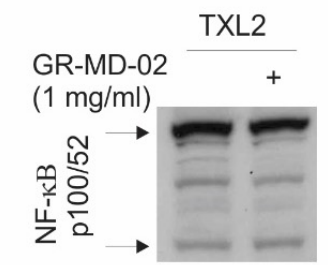

TXL2

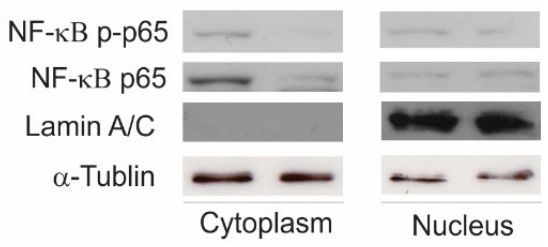

Figure 6. GM-CT-01 and GR-MD-02 attenuate mitogenic signaling in ALL cells. (a) ALL cells in co-culture with OP9 cells were treated with $20 \mathrm{mg} / \mathrm{ml} \mathrm{GM-CT-01} \mathrm{for} 2$ hours. ALL cells from underneath the stroma were assayed for cell surface expression of Galectin-3 using FACS: left, gating; right Galectin-3 cell surface positive cells in gate P2. Control, ALL cells underneath OP9 not treated with GM-CT-01. (b) Western blot analysis for Galectin-3 expression in K562 cells grown in suspension or plated on MEFs. Lanes 2 and 5, cells treated for 2 hours with $50 \mathrm{mM}$ lactose (lac); lane 4, cells treated for $2 \mathrm{hrs}$ with $20 \mathrm{mg} / \mathrm{ml}$ GM-CT-01 (GM). The histograms above lanes 3-5 represent densitometry using Image J. (c) Western blot analysis for Galectin-3 in US7 cells on day 20 of treatment with no drugs, with $2.5 \mathrm{nM}$ vincristine, with $1 \mathrm{mg} / \mathrm{ml} \mathrm{GM}-\mathrm{CT}-01$ or a combination, as indicated above the panel, while co-cultured with OP9 stroma. (d) Western blot analysis of US7 cells and TXL2 total cell lysates after incubation with $5 \mathrm{mg} / \mathrm{ml} \mathrm{GM-CT-01} \mathrm{for} 72$ hours in the presence of OP9 stromal cells. Blots were stripped and re-probed with Erk1/2, p38, Akt and Gapdh as loading controls. (e, f) US7 cells and TXL2 cells were incubated with $1 \mathrm{mg} / \mathrm{ml}$ GR-MD-02 for $72 \mathrm{hrs}$ in the presence of OP9 cells. Blots were stripped and reprobed with Erk1/2, p38, Akt and Gapdh as loading controls. (f) NF-kB p100/52, RelA NF-kB p-p65 and NF-kB p65 WB on TXL2 cytoplasmic and nuclear fractions. Lamin $A / C$ and $\alpha$-tubulin, loading controls for nuclear and cytoplasmic fractions, respectively. 

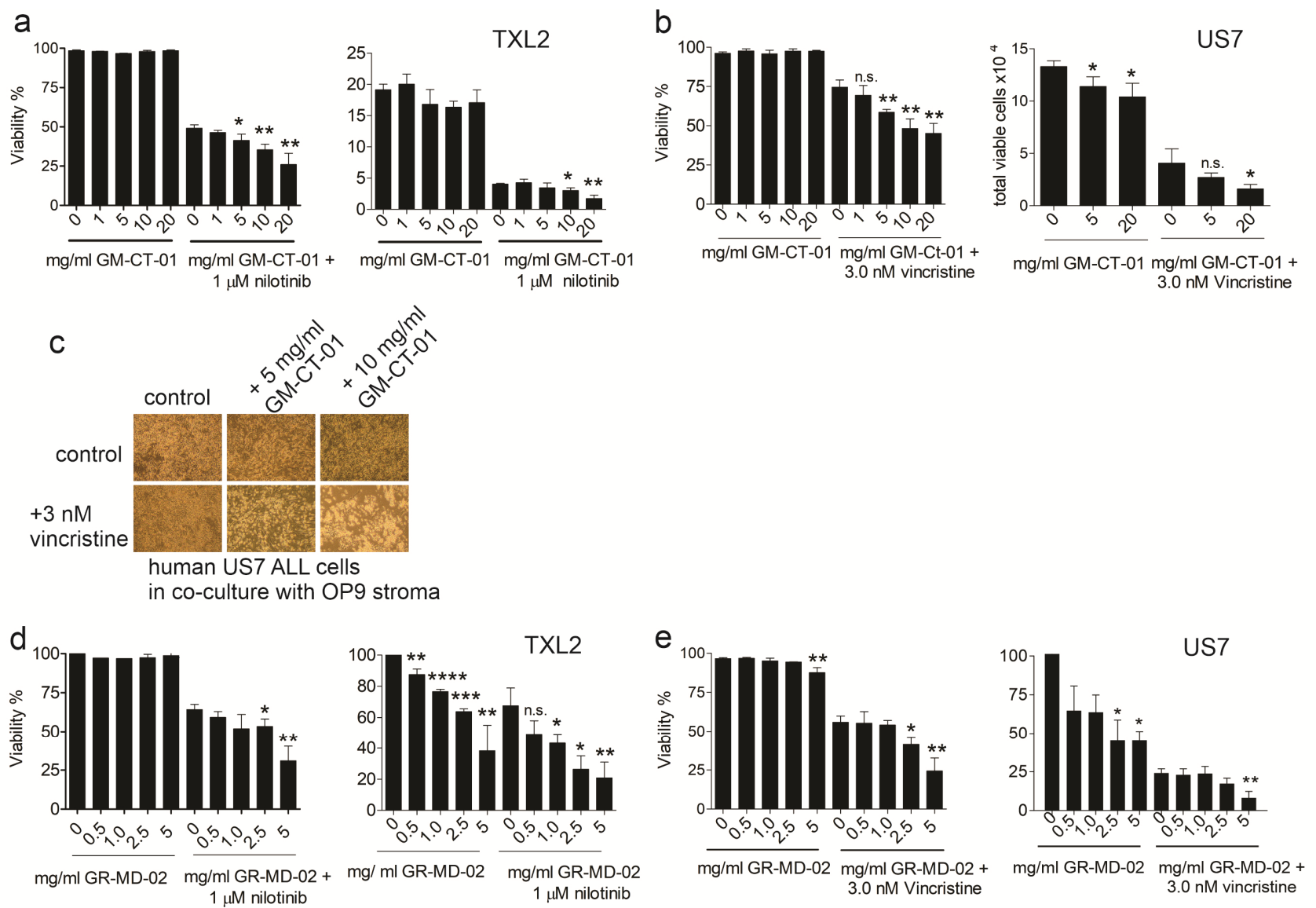

Figure 7. Combination drug treatment with GM-CT-01 or with GR-MD-02 inhibits proliferation of ALL cells. (a) Viability (left panel) and cell counts (right panel) of Ph-positive TXL-2 ALL cells treated with GM-CT-01 and nilotinib for 96 hours in the presence of OP9 cells. (b) Viability (left panel) and cell counts (right panel) of US7 cells treated for 96 hours with GM-CT-01 alone or in combination with vincristine in the presence of OP9 cells. (c) Phase contrast images of US7 cells co-cultured with irradiated OP9 stroma and treated with GM-CT-01 and vincristine as indicated. (d, e) Viability and cell counts of TXL2 cells (d) or US7 (e) treated with GR-MD-02 or a combination treatment as indicated. Viable cells and cell numbers determined using Trypan blue exclusion. ${ }^{*} p<0.05,{ }^{* *} p<0.01,{ }^{* *} p<0.01$, ${ }^{* * * *} p<0.0001$ compared to $0 \mathrm{mg} / \mathrm{ml}$ samples, representing treatment with nothing or only with nilotinib or vincristine, unpaired t-test. Control samples, DMSO at the same final concentration as the vincristine/nilotinib samples. 
a
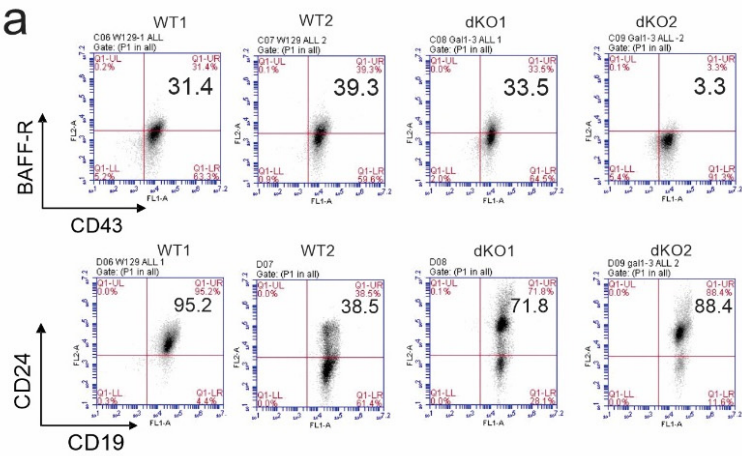

b
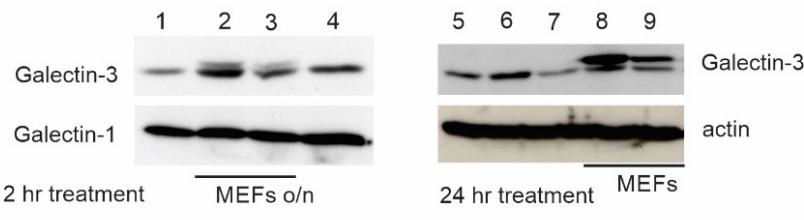

C CLUSTAL O(1.2.4) multiple sequence alignment

SP | P17931 | LEG3 HUMAN MADNFSLHDALSGSGNPNPQGWPGAWGNQPAGAGGYPGASYPGAYPGQAPPGAYPGQAPP 60

SP|P16110|LEG3_MOUSE MADSFSLNDALAGSGNPNPQGYPGAWGNQP-GAGGYPGAAYPGAYPGQAPPGAYPGQAPP 59

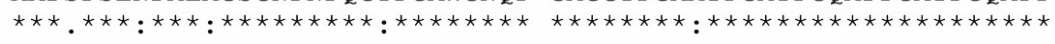

SP|P17931|LEG3 HUMAN GAYPGA-----------------PGAYPGAPAPGVYPGPPSGPGAYPSSGQPSATGA 100

SP|P16110|LEG3_MOUSE GAYPGQAPPSAYPGPTAPGAYPGPTAPGAYPGQPAPGAFPGQPGAPGAYP-----QCSGG 114

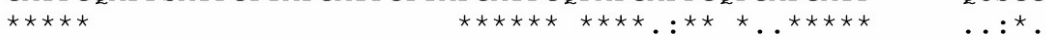

SP|P17931|LEG3 HUMAN YPATGPYGAPAGPLIVPYNLPLPGGVVPRMLITILGTVKPNANRIALDFQRGNDVAFHFN 160 SP|P16110|LEG3_MOUSE YPAAGPYGVPAGPLTVPYDLPLPGGVMPRMLITIMGTVKPNANRIVLDFRRGNDVAFHFN 174

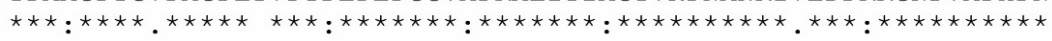

SP|P17931|LEG3 HUMAN PRFNENNRRVIVCNTKLDNNWGREERQSVFPFESGKPFKIQVLVEPDHFKVAVNDAHLLQ 220 SP IP16110|LEG3_MOUSE PRFNENNRRVIVCNTKQDNNWGKEERQSAFPFESGKPFKIQVLVEADHFKVAVNDAHLLQ 234

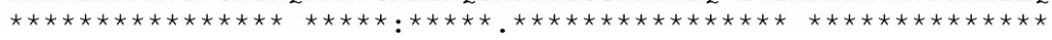

Figure S1. (a) FACS analysis of wt1, wt2, dKO1 and dKO2 murine BCP-ALL cells for the indicated cell surface markers. Numbers indicate the percentage cells in the upper right quadrant. (b) Western blot analysis of K562 cells grown alone or with irradiated MEFs overnight as indicated. Antibodies are indicated to the left and right of the panels. Actin, loading control. Lane 1 and lane 2, K562; lane $3 \mathrm{~K} 562$ incubated with $5 \mathrm{mg} / \mathrm{ml} \mathrm{GM-CT-01} \mathrm{for}$ 2 hours; lane $4 \mathrm{~K} 562$ incubated with $50 \mathrm{mM}$ lactose for 2 hours. Lane 5 and lane 8 , DMSO-treated K562; Lane 6 K562 exposed to $1 \mu \mathrm{M}$ nilotinib; lane 7 and lane 9, K562 treated with $2 \mathrm{mg} / \mathrm{ml}$ GM-CT-01 for 24 hours. (c) sequence alignment of human Galectin-3 and murine Galectin-3. 